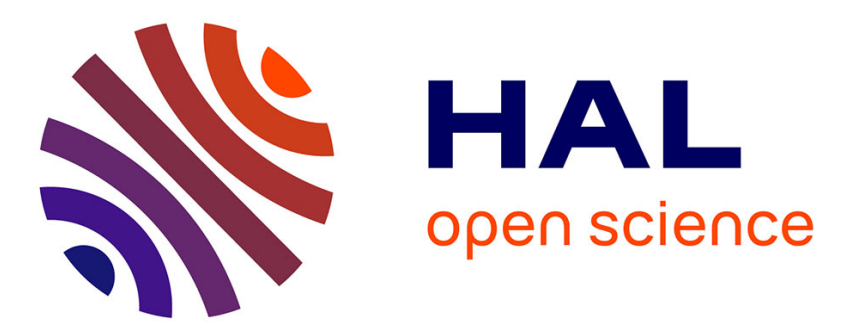

\title{
Thermal and volumetric properties of complex aqueous electrolyte solutions using the Pitzer formalism - The PhreeSCALE code
}

\author{
Adeline Lach, Faïza Boulahya, Laurent André, Arnault Lassin, Mohamed \\ Azaroual, Jean-Paul Serin, Pierre Cézac
}

\section{To cite this version:}

Adeline Lach, Faïza Boulahya, Laurent André, Arnault Lassin, Mohamed Azaroual, et al.. Thermal and volumetric properties of complex aqueous electrolyte solutions using the Pitzer formalism - The PhreeSCALE code. Computers \& Geosciences, 2016, 92, pp.58-69. 10.1016/j.cageo.2016.03.016 . hal-01315439

\author{
HAL Id: hal-01315439 \\ https://hal.science/hal-01315439
}

Submitted on 13 May 2016

HAL is a multi-disciplinary open access archive for the deposit and dissemination of scientific research documents, whether they are published or not. The documents may come from teaching and research institutions in France or abroad, or from public or private research centers.
L'archive ouverte pluridisciplinaire HAL, est destinée au dépôt et à la diffusion de documents scientifiques de niveau recherche, publiés ou non, émanant des établissements d'enseignement et de recherche français ou étrangers, des laboratoires publics ou privés. 


\section{Thermal and volumetric properties of complex aqueous electrolyte} solutions using the Pitzer formalism - The PhreeSCALE code

Adeline Lach $^{1,2^{*}}$, Faïza Boulahya ${ }^{1}$, Laurent André ${ }^{1}$, Arnault Lassin ${ }^{1}$, Mohamed Azaroual ${ }^{1}$, Jean-Paul Serin ${ }^{2}$, Pierre Cézac ${ }^{2}$

${ }^{1}$ BRGM - 3 avenue C. Guillemin - Orléans, France (A.Lach@brgm.fr, F.Boulahya@ brgm.fr,

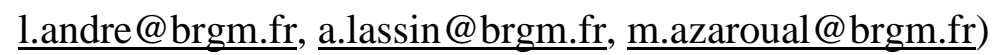

${ }^{2}$ LaTEP - rue Jules Ferry - Pau, France (pierre.cezac@univ-pau.fr, jean-paul.serin@univpau.fr)

\footnotetext{
* Corresponding author. email: A.Lach@brgm.fr, tel: +3323864 3157
} 
The thermal and volumetric properties of complex aqueous solutions are described according to the Pitzer equation, explicitly taking into account the speciation in the aqueous solutions. The thermal properties are the apparent relative molar enthalpy $\left(L_{\phi}\right)$ and the apparent molar heat capacity $\left(C_{p, \phi}\right)$. The volumetric property is the apparent molar volume $\left(V_{\phi}\right)$. Equations describing these properties are obtained from the temperature or pressure derivatives of the excess Gibbs energy and make it possible to calculate the dilution enthalpy $\left(\Delta \mathrm{H}^{D}\right)$, the heat capacity $\left(c_{p}\right)$ and the density $(\rho)$ of aqueous solutions up to high concentrations. Their implementation in PHREEQC V.3 (Parkhurst and Appelo, 2013) is described and has led to a new numerical tool, called PhreeSCALE. It was tested first, using a set of parameters (specific interaction parameters and standard properties) from the literature for two binary systems $\left(\mathrm{Na}_{2} \mathrm{SO}_{4}-\mathrm{H}_{2} \mathrm{O}\right.$ and $\left.\mathrm{MgSO}_{4}-\mathrm{H}_{2} \mathrm{O}\right)$, for the quaternary $\mathrm{K}-\mathrm{Na}-\mathrm{Cl}-\mathrm{SO}_{4}$ system (heat capacity only) and for the Na-K-Ca-Mg-Cl-SO $\mathrm{S}_{4}-\mathrm{HCO}_{3}$ system (density only). The results obtained with PhreeSCALE are in agreement with the literature data when the same standard solution heat capacity $\left(\mathrm{C}_{p}^{0}\right)$ and volume $\left(\mathrm{V}^{0}\right)$ values are used. For further applications of this improved computation tool, these standard solution properties were calculated independently, using the Helgeson-Kirkham-Flowers (HKF) equations. By using this kind of approach, most of the Pitzer interaction parameters coming from literature become obsolete since they are not coherent with the standard properties calculated according to the HKF formalism. Consequently a new set of interaction parameters must be determined. This approach was successfully applied to the $\mathrm{Na}_{2} \mathrm{SO}_{4}-\mathrm{H}_{2} \mathrm{O}$ and $\mathrm{MgSO}_{4}-\mathrm{H}_{2} \mathrm{O}$ binary systems, providing a new set of optimized interaction parameters, consistent with the standard solution properties derived from the HKF equations.

Keywords: PHREEQC, PhreeSCALE, Pitzer equation, heat capacity, density, $\mathrm{Na}_{2} \mathrm{SO}_{4}, \mathrm{MgSO}_{4}$ 
Nomenclature

\begin{tabular}{l|l}
\hline \multicolumn{2}{c}{ Subscript } \\
\hline$a, a^{\prime}, X$ & Anions \\
\hline$c, c^{\prime}, M$ & Cations \\
\hline$k$ & Ionic or neutral species \\
\hline$n, n^{\prime}, N$ & Neutral species \\
\hline$w$ & Water \\
\hline
\end{tabular}

\section{Symbols and units}

\begin{tabular}{|c|c|c|}
\hline$A_{\phi}$ & $\begin{array}{l}\text { Debye-Hückel parameter for osmotic } \\
\text { coefficient }\end{array}$ & kg.mol ${ }^{-1 / 2}$ \\
\hline$A_{L}$ & Debye-Hückel coefficient for enthalpy & J.kg.mol ${ }^{-3 / 2}$ \\
\hline$A_{J}$ & Debye-Hückel coefficient for heat capacity & $J . \mathrm{kg}^{1 / 2} \cdot \mathrm{K}^{-1} \cdot \mathrm{mol}^{-3 / 2}$ \\
\hline$A_{V}$ & Debye-Hückel coefficient for volume & $\mathrm{cm}^{3} \cdot \mathrm{kg}^{1 / 2} \cdot \mathrm{mol}^{-3 / 2}$ \\
\hline $\mathrm{b}$ & Universal Pitzer parameter & $1.2 \mathrm{~kg}^{1 / 2} \cdot \mathrm{mol}^{-1 / 2}$ \\
\hline$C_{p}^{\circ}$ & Standard heat capacity of solution & $J . K^{-1}$ \\
\hline$C_{p, \phi}$ & Apparent molar heat capacity of solution & $J . m o l^{-1} \cdot K^{-1}$ \\
\hline$C_{p, i}^{0}$ & $\begin{array}{l}\text { Standard partial molar heat capacity of the } \\
\text { species } i \text { at infinite dilution }\end{array}$ & $J . m o l^{-1} \cdot K^{-1}$ \\
\hline$C_{p}^{\prime}$ & Heat capacity of solution & $J . K^{-1}$ \\
\hline$c_{p}$ & Mass heat capacity of solution & $J \cdot g^{-1} \cdot K^{-1}$ \\
\hline$C_{p, w}^{\circ}$ & Heat capacity of pure water & $J . m o l^{-1} \cdot K^{-1}$ \\
\hline$c_{p, w}$ & Mass heat capacity of water & $J \cdot g^{-1} \cdot K^{-1}$ \\
\hline$e$ & Elementary charge & $1.60217653(14) \times 10^{-19} \mathrm{C}$ \\
\hline$\varepsilon_{0}$ & Electric constant & $8.854187817 \times 10^{-12} \mathrm{~F} . \mathrm{m}^{-1}$ \\
\hline$\epsilon$ & Dielectric constant of water & - \\
\hline$G^{e x}$ & Excess Gibbs energy & $J$ \\
\hline
\end{tabular}




\begin{tabular}{|c|c|c|}
\hline$I$ & Ionic strength & mol. $\mathrm{kg}^{-1}$ \\
\hline $\mathrm{k}$ & Boltzmann constant & $1.3806505(24) \times 10^{-23} J . K^{-1}$ \\
\hline$L$ & Relative enthalpy of solution & $J$ \\
\hline$L_{\phi}$ & $\begin{array}{l}\text { Apparent relative molar enthalpy of } \\
\text { solution }\end{array}$ & J.mol ${ }^{-1}$ \\
\hline$m_{i}$ & Molarity of species $\mathrm{i}$ & mol. $\mathrm{kg}^{-1}$ \\
\hline$M_{i}$ & Molar mass of species i & g.mol ${ }^{-1}$ \\
\hline$N_{A}$ & Avogadro number & $6.0221415(10) \times 10^{23} \mathrm{~mol}^{-1}$ \\
\hline$n_{i}$ & Number of moles of species $i$ & $m o l$ \\
\hline$v_{i}$ & Stoichiometric coefficient of species $i$ & - \\
\hline$P$ & Pressure & bar \\
\hline$R$ & Ideal gas constant & $8.314472(15) \mathrm{J}^{2} \mathrm{~mol}^{-1} \cdot \mathrm{K}^{-1}$ \\
\hline$R^{\prime}$ & Ideal gas constant & $83.14472(15) \mathrm{cm}^{3} \cdot$ bar.mol $^{-1} \cdot \mathrm{K}^{-1}$ \\
\hline$\rho_{w}$ & Water density & kg. $m^{-3}$ \\
\hline$\rho$ & Density of solution & g. $\mathrm{cm}^{-3}$ \\
\hline$T$ & Temperature & $K$ \\
\hline$V^{\circ}$ & Standard volume of the aqueous solution & $\mathrm{cm}^{3}$ \\
\hline$V_{i}^{\circ}$ & $\begin{array}{l}\text { Standard partial volume of the species } i \text { at } \\
\text { infinite dilution }\end{array}$ & $\mathrm{cm}^{3} \cdot \mathrm{mol}^{-1}$ \\
\hline$V_{\phi}$ & Molar apparent volume of solution & $\mathrm{cm}^{3} \cdot \mathrm{mol}^{-1}$ \\
\hline$w_{w}$ & Mass of water & $k g$ \\
\hline$z_{i}$ & Charge of species i & - \\
\hline
\end{tabular}




\section{Introduction}

Knowledge of the heat capacity and the density of electrolyte solutions is of interest in many fields. These parameters are necessary for geothermal process studies (Schröder et al., 2015) and in order to evaluate desalination process performance (Lin et al., 2014). Density data are also very important in $\mathrm{CO}_{2}$ sequestration studies (Bachu and Adams, 2003). They can all be obtained experimentally either by calorimetric measurements (Perron et al., 1975) or with a densimeter (Al Ghafri et al., 2012), or calculated from the temperature or the pressure derivative of the excess Gibbs energy. Some of the currently available software products that provide these values are:

- HSC Chemistry, developed by Outotec (2014), contains a module named AQUA that uses the Pitzer model to calculate the osmotic coefficient, the enthalpy, and the heat capacity of homogenous (single phase) aqueous electrolyte solutions.

- AQSOL001 (Aqueous Solutions ApS) can calculate the heat capacity of aqueous solutions. It is based on the eUNIQUAC model described by Thomsen (1997). The free downloadable version from their website includes $\mathrm{Na}^{+}, \mathrm{H}^{+}, \mathrm{OH}^{-}, \mathrm{Cl}^{-}, \mathrm{SO}_{4}{ }^{2-}$, and $\mathrm{HSO}_{4}{ }^{-}$. A version containing more species can be purchased.

- Wang et al. (2002) described a model that is the sum of three interaction terms: a longrange electrostatic term, a short-range term and a middle-range term. These are represented by a Pitzer-Debye-Hückel equation, the UNIQUAC model, and a symmetrical second virial coefficient-type expression, respectively. This model is included in OLI systems software that calculates thermodynamic properties (Gibbs free energy, enthalpy, entropy, heat capacity and volume) and derived thermodynamic properties (e.g. density, osmotic pressure). 
- Thermo-Calc (Andersson et al., 2002) calculates thermodynamic properties such as enthalpy and heat capacity. Two of this software's databases, AQS2 and TCAQ2, are dedicated to aqueous solutions. AQS2 contains 82 elements and the non-ideality of the aqueous solution phase is described using the complete revised HKF model (Helgeson-Kirkham-Flowers, Tanger and Helgeson, 1988), i.e. taking into account the Debye-Hückel Limiting Law term, ionic solvation, ionic association, as well as the binary, ternary and higher-order interaction terms. TCAQ2 contains 76 elements and the non-ideality of the aqueous solution phase is described using the extended SIT (Specific Interaction Theory) model, i.e. taking into account the Debye-Hückel Limiting Law term, as well as the binary, ternary and higher-order interaction terms.

- VOPO (Monnin, 1994), for VOlumetric PrOperties, calculates the density of natural waters. The major species $\left(\mathrm{Na}, \mathrm{K}, \mathrm{Ca}, \mathrm{Mg}, \mathrm{Cl}, \mathrm{SO}_{4}, \mathrm{HCO}_{3}\right.$ and $\mathrm{CO}_{3}$ ) are taken into account in this program, which is based on the Pitzer model and uses the specific interaction parameters determined by Monnin (1989) at $25^{\circ} \mathrm{C}$ and $1 \mathrm{bar}$.

Most of the software listed above includes either thermal or volumetric properties. Only the software developed by OLI systems calculates both. However, this software contains its own database and it is not possible to use it to define new parameters for unknown systems. We therefore developed software that is able to calculate thermal and volumetric properties of aqueous species and can be used to optimize interaction parameters.

PHREEQC V.3 (Parkhurst and Appelo, 2013), a geochemical calculation code widely used by geochemists, offers possibilities for new applications. In particular, studies that were limited to surface and shallow subsurface environments can now extend to deeper geological and geothermal environments and to industrial processes (by including pressure effects). PHREEQC code can calculate various water properties as activity coefficients of aqueous species and activity of water according to different formalisms including the Pitzer formalism. 
However, additional thermodynamic properties that are not yet included in PHREEQC, namely apparent relative molar enthalpy and heat capacity of solutions, are required for these new fields of application. On the other hand, the calculation of density was already implemented in the last version of the PHREEQC code. The authors used the HKFmoRR (Helgeson-Kirkham-Flowers-modified-Redlich-Rosenfeld) equation to compute the molar volume (Appelo et al., 2014):

$$
\mathrm{V}_{m, i}=V_{i}^{\circ}+A_{V} 0.5 z_{i}^{2} \frac{I^{0.5}}{1+\dot{a}_{i} B_{\gamma} I^{0.5}}+\left(b_{1, i}+\frac{b_{2, i}}{T-228}+b_{3, i}(T-228)\right) I^{b_{4, i}}
$$

Where $\dot{a}_{i}$ is the ion-size parameter, $B_{\gamma}$ is the Debye-length parameter and $b_{i}$ are for fitting the ionic strength dependence. And the apparent molar volume is calculated by:

$$
\mathrm{V}_{\phi}=\sum_{i} v_{i} \mathrm{~V}_{m, i}
$$

In this study, the apparent molar volume is calculated by:

$$
\mathrm{V}_{\phi}=\overline{V_{2}^{\circ}}+V^{e x}
$$

Where $V^{e x}$ is the excess molar volume calculated using the speciation and the volumetric interaction parameters following the Pitzer formalism. We chose to implement this approach in addition to that proposed by PHREEQC. Indeed, the thermal properties are calculated with the Pitzer's equations and the implementation of the Eq. (3) allows maintaining consistency in the formalism of properties calculation.

The aim of our work was to add to this software (PHREEQC) the calculation of apparent relative molar enthalpy, heat capacity, and density of complex aqueous solutions using the 
Pitzer formalism. The new numerical tool resulting from the present work is called PhreeSCALE.

The principal equations for calculating apparent relative molar enthalpy, heat capacity, and density of aqueous solutions are described below, followed by the modifications to PHREEQC. Then, the PhreeSCALE code is tested in two ways. First, the code is used to calculate the excess properties of several more or less complex chemical systems: all the apparent thermal and volumetric properties of the $\mathrm{Na}_{2} \mathrm{SO}_{4}-\mathrm{H}_{2} \mathrm{O}$ and $\mathrm{MgSO}_{4}-\mathrm{H}_{2} \mathrm{O}$ binary systems, the heat capacity of the Na-K-Cl- $\mathrm{SO}_{4}-\mathrm{H}_{2} \mathrm{O}$ system and the density of the Na-K-Ca$\mathrm{Mg}-\mathrm{Cl}-\mathrm{SO}_{4}-\mathrm{HCO}_{3}-\mathrm{H}_{2} \mathrm{O}$ system. During this first series of tests, the code is applied using Pitzer interaction parameters $\left(Y, Y^{L}, Y^{J}\right.$ and $\left.Y^{V}\right)$ and their standard properties $\left(Y^{0}\right)$ taken from literature in order to show that the new equations are correctly implemented in the code.

In a second part of this work, we demonstrate that the Pitzer equations can be used in combination with the HKF model which calculates the standard partial molar thermodynamic properties of aqueous species. But, the sets of interaction parameters coming from literature are generally not consistent with the calculated standard molar properties. Consequently they must be revised when necessary. PhreeSCALE is then coupled with the PEST optimization software (Doherty, 2004) in order to optimize new Pitzer interaction parameters from heat capacity and osmotic coefficient data, or density data. This is on the case of the $\mathrm{Na}_{2} \mathrm{SO}_{4}-\mathrm{H}_{2} \mathrm{O}$ and $\mathrm{MgSO}_{4}-\mathrm{H}_{2} \mathrm{O}$ binary systems, for which we propose a new set of interaction parameters. 


\section{Theory}

The thermodynamic properties of aqueous solutions, such as the osmotic coefficient, heat capacity or density, can be obtained by deriving the excess Gibbs free energy with respect to temperature or pressure. We use the Pitzer model (Pitzer, 1991) to describe the excess Gibbs energy of aqueous solutions, $G^{e x}$ (Eq. 4) and all the aforementioned thermodynamic properties are calculated using the same theoretical framework.

$$
\mathrm{G}^{e x} /\left(w_{w} R T\right)=\left\{\begin{array}{c}
-\frac{4 I A_{\phi}}{b} \ln \left(1+b I^{1 / 2}\right)+2 \sum_{c} \sum_{a} m_{c} m_{a}\left(B_{c a}+\left(\sum_{c} m_{c} z_{c}\right) C_{c a}\right) \\
+\sum_{c} \sum_{c^{\prime}} m_{c} m_{c^{\prime}}\left(2 \Phi_{c c^{\prime}}+\sum_{a} m_{a} \psi_{c c^{\prime} a}\right) \\
+\sum_{a} \sum_{a^{\prime}} m_{a} m_{a^{\prime}}\left(2 \Phi_{a a^{\prime}}+\sum_{c} m_{c} \psi_{a a c^{\prime}}\right) \\
+\sum_{n} m_{n}^{2} \lambda_{n n}+\sum_{n} m_{n}^{3} \mu_{n n n} \\
+2 \sum_{n} \sum_{n^{\prime}} m_{n} m_{n^{\prime}} \lambda_{n n^{\prime}}+3 \sum_{n} \sum_{n^{\prime}} m_{n}^{2} m_{n^{\prime}} \mu_{n n n '} \\
+6 \sum_{n} \sum_{n^{\prime}} \sum_{n^{\prime}} m_{n} m_{n^{\prime}} m_{n} \mu_{n n n^{\prime \prime}} \\
+2 \sum_{n} \sum_{c} m_{n} m_{c} \lambda_{n c}+3 \sum_{n} \sum_{c} m_{n}^{2} m_{c} \mu_{n n c} \\
+2 \sum_{n} \sum_{a} m_{n} m_{a} \lambda_{n a}+3 \sum_{n} \sum_{a} m_{n}^{2} m_{a} \mu_{n n a} \\
+\sum_{n} \sum_{c} \sum_{a} m_{n} m_{c} m_{a} \zeta_{n c a} \\
+\sum_{n} \sum_{c} \sum_{c^{\prime}} m_{n} m_{c} m_{c^{\prime}} \eta_{n c c \prime} \\
+\sum_{n} \sum_{a} \sum_{a^{\prime}} m_{n} m_{c} m_{a^{\prime}} \eta_{n a a \prime} \\
+6 \sum_{c} \sum_{n} \sum_{n^{\prime}} m_{c} m_{n} m_{n^{\prime}} \mu_{c n n '} \\
+6 \sum_{a} \sum_{n} \sum_{n^{\prime}} m_{a} m_{n} m_{n^{\prime}} \mu_{a n n^{\prime}}
\end{array}\right\}
$$

The different parameters $\left(A_{\phi}, B_{c a} \ldots\right)$ are not detailed here but they are summarized in the appendix of Lach et al. (2015).

The temperature dependence of every interaction parameter is assumed to have the following expression (which is a combination of equations from Møller (1988) and Christov and Møller (2004)):

$$
\begin{gathered}
Y(T)=a_{1}+a_{2} T+a_{3} T^{2}+a_{4} T^{3}+a_{5} / T+a_{6} \ln T+a_{7} /(T-263) \\
+a_{8} /(680-T)+a_{9} /(T-227)
\end{gathered}
$$

where Y designates any of the adjustable specific interaction parameters. 
The heat capacity $\left(c_{p}\right)$ and the density of the solution $(\rho)$ are measurable properties and must therefore be described formally. They can be calculated from the apparent molar heat capacity $\left(C_{p, \phi}\right)$ and the apparent molar volume $\left(V_{\phi}\right)$, respectively, which are obtained from the derivatives of excess Gibbs energy.

\subsection{Apparent properties}

The apparent property $\left(Z_{\phi}\right)$ is defined by the following equation (Hubert et al., 1995):

$$
Z_{\phi}=\left(Z\left(n_{w}, \sum_{i \neq w} n_{i}\right)-Z\left(n_{w}, 0\right)\right) / \sum_{i \neq w} n_{i}
$$

where $Z\left(n_{w}, \sum_{i \neq w} n_{i}\right)$ is the property value of a solution containing $n_{w}$ moles of solvent and $\sum_{i \neq w} n_{i}$ moles of solutes and $Z\left(n_{w}, 0\right)$ is the value of the property in the pure solvent.

\subsection{The apparent relative molar enthalpy}

The relative enthalpy ( $L$ ) of an electrolyte solution is related to $G^{\text {ex }}$ by Eq. (7) (Pitzer, 1991).

$$
L=-T^{2}\left[\partial\left(\frac{G^{e x}}{T}\right) / \partial T\right]_{P, m}
$$

Using Eq. (6) and since the relative enthalpy is null for the pure solvent solution:

$$
L_{\phi}=L / \sum_{i \neq w} n_{i}
$$

Therefore, applying Eq. (7-8) to Eq. (4), the apparent relative molar enthalpy is calculated by the following equation: 


$$
L_{\phi}=\left(\frac{R T^{2}}{\sum_{i} m_{i}}\right)\left\{\begin{array}{c}
I \frac{A_{L}}{R T^{2}} \frac{\ln \left(1+b I^{1 / 2}\right)}{b}-2 \sum_{c} \sum_{a} m_{c} m_{a}\left(B_{c a}^{L}+\left(\sum_{c} m_{c} z_{c}\right) C_{c a}^{L}\right) \\
-\sum_{c} \sum_{c^{\prime}} m_{c} m_{c^{\prime}}\left(2 \Phi_{c c^{\prime}}^{L}+\sum_{a} m_{a} \psi_{c c^{\prime} a}^{L}\right) \\
-\sum_{a} \sum_{a^{\prime}} m_{a} m_{a^{\prime}}\left(2 \Phi_{a a^{\prime}}^{L}+\sum_{c} m_{c} \psi_{a a^{\prime} c}^{L}\right) \\
-\sum_{n} m_{n}^{2} \lambda_{n n}^{L}-\sum_{n} m_{n}^{3} \mu_{n n n}^{L} \\
-2 \sum_{n} \sum_{n^{\prime}} m_{n} m_{n^{\prime}} \lambda_{n n^{\prime}}^{L}-3 \sum_{n} \sum_{n^{\prime}} m_{n}^{2} m_{n^{\prime}} \mu_{n n n^{\prime}}^{L} \\
-6 \sum_{n} \sum_{n^{\prime}} \sum_{n} m_{n} m_{n^{\prime}} m_{n^{\prime \prime}} \mu_{n n^{\prime} n^{\prime \prime}}^{L} \\
-2 \sum_{n} \sum_{c} m_{n} m_{c} \lambda_{n c}^{L}-3 \sum_{n} \sum_{c} m_{n}^{2} m_{c} \mu_{n n c}^{L} \\
-2 \sum_{n} \sum_{a} m_{n} m_{a} \lambda_{n a}^{L}-3 \sum_{n} \sum_{a} m_{n}^{2} m_{a} \mu_{n n a}^{L} \\
-\sum_{n} \sum_{c} \sum_{a} m_{n} m_{c} m_{a} \zeta_{n c a}^{L} \\
-\sum_{n} \sum_{c} \sum_{c^{\prime}} m_{n} m_{c} m_{c^{\prime}} \eta_{n c c^{\prime}}^{L} \\
-\sum_{n} \sum_{a} \sum_{a^{\prime}} m_{n} m_{c} m_{a^{\prime}} \eta_{n a a \prime}^{L} \\
-6 \sum_{c} \sum_{n} \sum_{n^{\prime}} m_{c} m_{n} m_{n^{\prime}} \mu_{c n n^{\prime}}^{L} \\
-6 \sum_{a} \sum_{n} \sum_{n^{\prime}} m_{a} m_{n} m_{n^{\prime}} \mu_{a n n^{\prime}}^{L}
\end{array}\right\}
$$

where:

$$
A_{L}=4 R T^{2}\left(\partial A_{\phi} / \partial T\right)
$$

and

$$
Y^{L}(T)=\frac{\partial Y}{\partial T}
$$

\subsection{The apparent molar heat capacity}

The heat capacity is related to the relative enthalpy by the following equation (Pitzer, 1991):

$$
C_{p}^{\prime}=C_{p}^{\circ}+(\partial L / \partial T)_{P, m}
$$

where $C_{p}^{\circ}$ is a linear combination of the standard molar heat capacities of the solvent and the solutes. Therefore:

$$
C_{p}^{\prime}=n_{w} C_{p, w}^{\circ}+\sum_{i} n_{i} C_{p, i}^{0}+(\partial L / \partial T)_{P, m}
$$


Following Eq.(6), the apparent heat capacity of a multicomponent solution, $C_{p, \phi}$, is defined by the following equation:

$$
C_{p, \phi}=\left(C_{p}^{\prime}-n_{w} C_{p, w}^{\circ}\right) / \sum_{i} n_{i}
$$

Combining Eq. (13) and Eq. (14), we obtain:

$$
C_{p, \phi}=\left(\sum_{i} n_{i} C_{p, i}^{0}\right) / \sum_{i} n_{i}+\left(\partial\left(\frac{L}{\sum_{i} n_{i}}\right) / \partial T\right)_{P, m}
$$

Using Eq. (8), the heat capacity is related to the apparent relative molar enthalpy by the following equation:

$$
C_{p, \phi}=\overline{C_{p 2}^{\circ}}+\left(\partial L_{\phi} / \partial T\right)_{P, m}
$$

Here, $\overline{C_{p 2}^{\circ}}$ is the standard partial heat capacity of all of the solutes at infinite dilution:

$$
\overline{C_{p 2}^{\circ}}=\left(\sum_{i} m_{i} C_{p, i}^{0}\right) / \sum_{i} m_{i}
$$

where $C_{p, i}^{0}$ is calculated with the equation of Helgeson et al. (1981) summarized in Johnson et al. (1992).

Therefore, applying Eq. (16) to Eq. (9) gives the following equation for the apparent heat capacity: 


$$
C_{p, \phi}=\overline{C_{p 2}^{\circ}}+\left(\frac{R T^{2}}{\sum_{i} m_{i}}\right)\left\{\begin{array}{c}
I \frac{A_{J}}{R T^{2}} \frac{\ln \left(1+b I^{1 / 2}\right)}{b}-2 \sum_{c} \sum_{a} m_{c} m_{a}\left(B_{c a}^{J}+\left(\sum_{c} m_{c} z_{c}\right) C_{c a}^{J}\right) \\
-\sum_{c} \sum_{c^{\prime}} m_{c} m_{c^{\prime}}\left(2 \Phi_{c c^{\prime}}^{J}+\sum_{a} m_{a} \psi_{c c^{\prime} a}^{J}\right) \\
-\sum_{a} \sum_{a^{\prime}} m_{a} m_{a^{\prime}}\left(2 \Phi_{a a^{\prime}}^{J}+\sum_{c} m_{c} \psi_{a a^{\prime} c}^{J}\right) \\
-\sum_{n} m_{n}^{2} \lambda_{n n}^{J}-\sum_{n} m_{n}^{3} \mu_{n n n}^{J} \\
-2 \sum_{n} \sum_{n^{\prime}} m_{n} m_{n^{\prime}} \lambda_{n n^{\prime}}^{J}-3 \sum_{n} \sum_{n^{\prime}} m_{n}^{2} m_{n^{\prime}} \mu_{n n n^{\prime}}^{J} \\
-6 \sum_{n} \sum_{n^{\prime}} \sum_{n} m_{n} m_{n^{\prime}} m_{n} \mu_{n n \prime n^{\prime \prime}}^{J} \\
-2 \sum_{n} \sum_{c} m_{n} m_{c} \lambda_{n c}^{J}-3 \sum_{n} \sum_{c} m_{n}^{2} m_{c} \mu_{n n c}^{J} \\
-2 \sum_{n} \sum_{a} m_{n} m_{a} \lambda_{n a}^{J}-3 \sum_{n} \sum_{a} m_{n}^{2} m_{a} \mu_{n n a}^{J} \\
-\sum_{n} \sum_{c} \sum_{a} m_{n} m_{c} m_{a} \zeta_{n c a}^{J} \\
-\sum_{n} \sum_{c} \sum_{c^{\prime}} m_{n} m_{c} m_{c^{\prime}} \eta_{n c c^{\prime}}^{J} \\
-\sum_{n} \sum_{a} \sum_{a^{\prime}} m_{n} m_{c} m_{a^{\prime}} \eta_{n a a_{\prime}^{\prime}}^{J} \\
-6 \sum_{c} \sum_{n} \sum_{n^{\prime}} m_{c} m_{n} m_{n^{\prime}} \mu_{c n n^{\prime}}^{J} \\
-6 \sum_{a} \sum_{n} \sum_{n^{\prime}} m_{a} m_{n} m_{n^{\prime}} \mu_{a n n^{\prime}}^{J} \\
\quad
\end{array}\right\}
$$

where:

$$
A_{J}=(2 / T) A_{L}+4 R T^{2}\left(\partial^{2} A_{\phi} / \partial T^{2}\right)
$$

And:

$$
Y^{J}=\frac{\partial Y^{L}}{\partial T}+\frac{2}{T} Y^{L}
$$

The mass heat capacity of the solution $\left(c_{p}\right)$ can then be calculated from the apparent heat capacity using the following equation:

$$
c_{p}=\frac{C_{p, \phi} \sum_{i} m_{i}+1000 c_{p, w}}{1000+\sum_{i} m_{i} M_{i}}
$$

\subsection{The apparent molar volume}

The volume of an electrolyte solution $(V)$ is related to $G^{e x}$ by Eq. (22): 


$$
V=V^{\circ}+\left[\partial G^{e x} / \partial P\right]_{T, m}
$$

where $V^{\circ}$ is a linear combination of the standard volume of the solvent and the solutes. Therefore:

$$
V=n_{w} V_{w}^{\circ}+\sum_{i} n_{i} V_{i}^{\circ}+\left[\partial G^{e x} / \partial P\right]_{T, m}
$$

Following Eq. (6), the apparent molar volume is expressed by the equation:

$$
V_{\phi}=\left(\mathrm{V}-n_{w} V_{w}^{\circ}\right) / \sum_{i} n_{i}
$$

Therefore:

$$
V_{\phi}=\overline{V_{2}^{\circ}}+\left[\partial G^{e x} / \partial P\right]_{T, m} / \sum_{i} n_{i}
$$

where $\overline{V_{2}^{\circ}}$ is the standard partial volume of all solutes at infinite dilution:

$$
\overline{V_{2}^{\circ}}=\left(\sum_{i} m_{i} V_{i}^{\circ}\right) / \sum_{i} m_{i}
$$

Applying Eq. (25) to Eq. (4) gives the following equation for the apparent molar volume of any aqueous solution: 


$$
V_{\phi}=\overline{V_{2}^{\circ}}+\left(\frac{R^{\prime} T}{\sum_{i} m_{i}}\right)\left\{\begin{array}{c}
\frac{I A_{V}}{R^{\prime} T} \frac{\ln \left(1+b I^{1 / 2}\right)}{b}+2 \sum_{c} \sum_{a} m_{c} m_{a}\left(B_{c a}^{V}+\left(\sum_{c} m_{c} z_{c}\right) C_{c a}^{V}\right) \\
+\sum_{c} \sum_{c^{\prime}} m_{c} m_{c^{\prime}}\left(2 \Phi_{c c^{\prime}}^{V}+\sum_{a} m_{a} \psi_{c c^{\prime a}}^{V}\right) \\
+\sum_{a} \sum_{a^{\prime}} m_{a} m_{a^{\prime}}\left(2 \Phi_{a a^{\prime}}^{V}+\sum_{c} m_{c} \psi_{a a \prime c}^{V}\right) \\
+\sum_{n} m_{n}^{2} \lambda_{n n}^{V}+\sum_{n} m_{n}^{3} \mu_{n n n}^{V} \\
+2 \sum_{n} \sum_{n^{\prime}} m_{n} m_{n^{\prime}} \lambda_{n n^{\prime}}^{V}+3 \sum_{n} \sum_{n^{\prime}} m_{n}^{2} m_{n^{\prime}} \mu_{n n n '}^{V} \\
+6 \sum_{n} \sum_{n^{\prime}} \sum_{n} m_{n} m_{n^{\prime}} m_{n} \mu_{n n n^{\prime \prime}}^{V} \\
+2 \sum_{n} \sum_{c} m_{n} m_{c} \lambda_{n c}^{V}+3 \sum_{n} \sum_{c} m_{n}^{2} m_{c} \mu_{n n c}^{V} \\
+2 \sum_{n} \sum_{a} m_{n} m_{a} \lambda_{n a}^{V}+3 \sum_{n} \sum_{a} m_{n}^{2} m_{a} \mu_{n n a}^{V} \\
+\sum_{n} \sum_{c} \sum_{a} m_{n} m_{c} m_{a} \zeta_{n c a}^{V} \\
+\sum_{n} \sum_{c} \sum_{c^{\prime}} m_{n} m_{c} m_{c^{\prime}} \eta_{n c c^{\prime}}^{V} \\
+\sum_{n} \sum_{a} \sum_{a^{\prime}} m_{n} m_{c} m_{a^{\prime}} \eta_{n a a \prime}^{V} \\
+6 \sum_{c} \sum_{n} \sum_{n^{\prime}} m_{c} m_{n} m_{n^{\prime}} \mu_{c n n \prime}^{V} \\
+6 \sum_{a} \sum_{n} \sum_{n^{\prime}} m_{a} m_{n} m_{n^{\prime}} \mu_{a n n^{\prime}}^{V}
\end{array}\right\}
$$

where:

$$
A_{V}=-4 R^{\prime} T\left(\partial A_{\phi} / \partial P\right)
$$

Technically, the volumetric interaction parameters are the pressure derivatives of the interaction parameters:

$$
Y^{V}=(\partial Y / \partial P)
$$

However, so far, the interaction parameters as given by Eq. (5) are considered to be independent of pressure. Therefore, despite the fact that it is not consistent with Eq. (5), an additional independent set of parameters is included in the database to account for temperature-variable pressure effects. Many authors have proposed different temperature dependences for these parameters (Krumgalz, 2000; Saluja et al., 1995). We chose the one proposed by Phutela and Pitzer (1986b) which can be formally made compatible with Eq. (5):

$$
Y^{V}=b_{0} / T+b_{1}+b_{2} T+b_{3} T^{2}+b_{4} T^{3}+b_{5} P_{-} b a r
$$


Integrating Eq. (30), makes it possible to link the coefficients $b_{i}$ with the coefficient $a_{i}$ (Eq. (5)) by the following expression:

$$
\begin{aligned}
& a_{1}=b_{1} P+\frac{b_{5}}{2} P^{2}+c_{1} ; a_{2}=b_{2} P+c_{2} ; a_{3}=b_{3} P+c_{3} ; a_{4}=b_{4} P+c_{4} ; a_{5}= \\
& b_{0} P+c_{5}
\end{aligned}
$$

However, our interaction parameters are determined at 1 bar below $100{ }^{\circ} \mathrm{C}$ and at saturation pressure above $100{ }^{\circ} \mathrm{C}$, as is very often done. Therefore, there is an implicit pressure dependence which is not compatible with Eq. (31). Indeed, knowing $a_{i}$ and $b_{i}$ coefficients, it is not possible to determine one $c_{i}$ coefficient that is valid at both 1 bar and saturation pressure. The entire set of interaction parameters must be re-optimized, which is beyond the scope of this work. Therefore, we continued to use pressure-independent interaction parameters.

From the apparent molar volume, the density of the solution can be calculated with the equation:

$$
\rho=\left(1000+\sum_{i} m_{i} M_{i}\right) /\left(V_{\phi} \sum_{i} m_{i}+10^{6}\left(\rho_{w}\right)^{-1}\right)
$$

All of the above equations, and specifically Eq. (9), (18), and (27), can theoretically be applied to any complex aqueous solution. Indeed, all possible aqueous speciation, including neutral species, is considered. As such, these equations represent an extension of the theoretical work of Felmy and Weare (1986), Pabalan and Pitzer (1988), Monnin (1989), and Pitzer (1991). 


\section{Computer program: PHREEQC modification}

PHREEQC V3 (Parkhurst and Appelo, 2013) was modified to include the equations described above, and the new version is called PhreeSCALE.

\subsection{The sources}

The temperature dependence of interaction parameters was modified in accordance with Eq. (5) and the temperature dependence of the derived interaction parameters were added in accordance with Eq. (16) and Eq. (25) together with the volumetric interaction parameters (Eq. (30)). The apparent properties and the equations necessary for computing were also added (the temperature and pressure derivatives of the dielectric constant and the density of pure water, the heat capacity of water, the standard partial molar heat capacity and the volume of aqueous species at infinite dilution, etc.). The equation for calculating the osmotic coefficient was also modified to take into account partial dissociation (Lach et al., 2015) according to the following equation:

$$
\phi^{\text {PhreesCALE }}=\phi^{\text {Phreeqc }} \sum_{i} m_{i} / \sum_{i} v_{i} m_{i}
$$

where $v_{i}$ is the number of moles of ions formed by the complete dissociation of one molecule of solute.

\subsection{The database}

In order to run PhreeSCALE, parameters used in the new equations must be readable from the associated thermodynamic database. One line is therefore added to each species with the keyword HKF in the SOLUTION_SPECIES block. It gathers 8 parameters: the 7 HKF parameters $\left(a_{1}, a_{2}, a_{3}, a_{4}, c_{1}, c_{2}, \omega_{T r, P r}\right)$ used to calculate the standard partial molar heat capacity and the volume of any aqueous species $i$ at infinite dilution (Helgeson et al., 1981) 
and one additional parameter corresponding to $v_{i}$ in Eq. (33). The first seven parameters can be found in the Thermoddem database (Blanc et al., 2012). The energy unit is the Joule. The volumetric interaction parameters in the PITZER block were also added, which required the creation of the corresponding keywords B0V, B1V, B2V, C0V, THETAV, LAMDAV, ZETAV, PSIV, MUV and ETAV.

\subsection{Selected output}

Several new output key words were created and correspond to each property. They can be called in the SELECTED_OUTPUT block (declared in the input file) in order to write the corresponding properties in a selected output file. These keywords are described in Table 1. 


\section{Results}

\subsection{PhreeSCALE validation using interaction parameters from literature}

Before any practical application of the code, the first task to achieve is checking the program. To do so, we used PhreeSCALE with sets of interaction parameters available in the literature and compared our results to those obtained by the same authors. The test covers four chemical systems with respect to various interaction parameters $\left(\mathrm{Y}, \mathrm{Y}^{L}, \mathrm{Y}^{J}\right.$ and $\left.\mathrm{Y}^{V}\right)$ and standard properties $\left(\mathrm{C}_{p}^{0}\right.$ and $\left.\mathrm{V}^{0}\right)$. The first chemical system is the $\mathrm{Na}_{2} \mathrm{SO}_{4}-\mathrm{H}_{2} \mathrm{O}$ binary system for which Rogers and Pitzer (1981) gave interaction parameters to calculate the osmotic coefficient, the apparent relative molar enthalpy and the apparent molar heat capacity. In addition, Phutela and Pitzer (1986b) measured the volumetric properties and determined the volumetric interaction parameters for the same system. The second system is the 2-2 type $\mathrm{MgSO}_{4}-\mathrm{H}_{2} \mathrm{O}$ binary system, for which Phutela and Pitzer (1986a, 1986b) measured the volumetric properties and determined the volumetric interaction parameters. The third system considered for checking the program implemented in PhreeSCALE is the $\mathrm{Na}-\mathrm{K}-\mathrm{Cl}-\mathrm{SO}_{4}-\mathrm{H}_{2} \mathrm{O}$ system for which Conti et al., $(1989,1986)$ determined the interaction parameters for calculating the heat capacity. Finally, the system Na-K-Ca-Mg-Cl-SO $-\mathrm{SCO}_{3}-\mathrm{H}_{2} \mathrm{O}$ is considered in order to check the calculation of density at $25{ }^{\circ} \mathrm{C}$ using the parameters of Monnin (1989).

To compare the values of a property $x$ for a data point $i$ calculated by the different authors (superscript "cal") and by PhreeSCALE (superscript "PhreeSCALE"), the absolute value of average relative deviation is calculated with the following equation:

$$
\Delta_{A A D}=(1 / N) \sum_{i}^{N}\left|\left(x_{i}^{c a l}-x_{i}^{\text {PhreesCALE }}\right) / x_{i}^{c a l}\right|
$$

where $\mathrm{N}$ is the total number of data points. 
If the comparison concerns apparent properties, it can be necessary to correct the values computed by PhreeSCALE in order to make them compatible. Indeed, in this study the apparent properties are computed considering the ionic species. Authors like Phutela and Pitzer (1986a, 1986b) or Rogers and Pitzer (1981) consider the electrolyte instead the ionic species. The correction to make results from the unicity of a solution property $\left(c_{p}\right.$ or $\left.\rho\right)$ :

$$
c_{p}^{\text {litt }}=c_{p}^{\text {PhreeSCALE }}
$$

Where $c_{p}^{\text {litt }}$ correspond at the heat capacity provides by the literature.

Using Eq. (21) gives:

$$
\frac{C_{p, \phi}^{l i t t} \sum_{k} m_{k}+1000 c_{p, w}}{1000+\sum_{k} m_{k} M_{k}}=\frac{C_{p, \phi}^{\text {PhreeSCALE }} \sum_{i} m_{i}+1000 c_{p, w}}{1000+\sum_{i} m_{i} M_{i}}
$$

where the subscript $k$ refers to an electrolyte and the subscript $i$ to an ionic species. As the denominator is identical in the two members of Eq. (36), it comes:

$$
C_{p, \phi}^{\text {litt }}=\frac{C_{p, \phi}^{\text {PhreesCALE }} \sum_{i} m_{i}}{\sum_{k} m_{k}}
$$

The same demonstration can be made on the density. Finally, the more general relationship can be written:

$$
Y_{\phi}^{l i t t}=\delta . Y_{\phi}^{\text {PhreesCALE }}
$$

Where:

$$
\delta=\frac{\sum_{i} m_{i}}{\sum_{k} m_{k}}
$$


For instance, in the case of $\mathrm{Na}_{2} \mathrm{SO}_{4}$ the value computed by PhreeSCALE must be multiplied by 3 to be compared with the value proposed by Phutela and Pitzer (1986a) and Rogers and Pitzer (1981):

$$
Y_{\phi}^{\text {litt }}=\left(\frac{m_{\mathrm{Na}^{+}}+m_{S \mathrm{SO}_{4}^{2-}}}{m_{\mathrm{Na}_{2} \mathrm{SO}_{4}}}\right) \cdot Y_{\phi}^{\text {PhreesCALE }}
$$

Since $m_{\mathrm{Na}^{+}}=2 * m_{\mathrm{Na}_{2} \mathrm{SO}_{4}}$ and $m_{\mathrm{SO}_{4}^{2-}}=m_{\mathrm{Na}_{2} \mathrm{SO}_{4}}$, Eq. (40) becomes:

$$
Y_{\phi}^{l i t t}=3 . Y_{\phi}^{\text {PhreesCALE }}
$$

At last, the standard deviation of each case is summarized in Table 2. On the binary systems, the largest deviation (2\%) is obtained for the apparent molar heat capacities of $\mathrm{MgSO}_{4}-\mathrm{H}_{2} \mathrm{O}$ system at 20 bar. For more complex system, the properties of solution are well calculated. Indeed, the largest deviation is equal to $0.415 \%$ for the heat capacities of $\mathrm{Na}-\mathrm{K}-\mathrm{Cl}-\mathrm{SO}_{4}-\mathrm{H}_{2} \mathrm{O}$ system.

In conclusion, the new code PhreeSCALE is able to calculate the thermal and volumetric properties of complex solutions using the Pitzer interaction parameters released by the authors.

\subsection{Optimization of interaction parameters}

In many studies of brine systems, the standard properties $\left(\mathrm{C}_{p}^{0}\right.$ and $\left.\mathrm{V}^{0}\right)$ are considered as adjustable parameters. The authors use these parameters to optimize their fit of numerical results with experimental data. This approach can lead to inconsistencies of these standard properties with values determined elsewhere in the literature. In order to avoid this, standard properties can be selected from reference studies and thus be excluded from the parameterization procedure. In the present study, we chose to use the HKF formalism (Helgeson et al., 1981) to calculate the standard properties. The consequence of using this 
approach is a loss of coherency between the standard properties and the set of interaction parameters proposed by the authors. A new set of interaction parameters compatible with the calculated $\mathrm{C}_{p}^{0}$ and $\mathrm{V}^{0}$ values must therefore be determined. This is what we did for the two binary systems: $\mathrm{Na}_{2} \mathrm{SO}_{4}-\mathrm{H}_{2} \mathrm{O}$ and $\mathrm{MgSO}_{4}-\mathrm{H}_{2} \mathrm{O}$.

\subsubsection{The $\mathrm{Na}_{2} \mathrm{SO}_{4}-\mathrm{H}_{2} \mathrm{O}$ binary system}

In Fig. 1, the standard partial molar properties (heat capacity and volume) of the $\mathrm{Na}_{2} \mathrm{SO}_{4}$ electrolyte are plotted as a function of temperature at saturation pressure. Symbols represent the $C_{p}^{0}$ and $V^{0}$ values optimized by Rogers and Pitzer (1981) and Phutela and Pitzer (1986b), respectively, and lines represent values calculated with the HKF equations (Helgeson et al. (1981); Johnson et al. (1992)). Despite the fact that results are generally consistent, a nonnegligible difference can be observed for the standard heat capacity over the entire temperature range, which may have significant consequences on the description of the heat capacity of $\mathrm{Na}_{2} \mathrm{SO}_{4}$ solutions. This is confirmed in Fig. 2 in which experimental data from the literature (diamonds) are plotted together with values calculated (dotted-line) using the standard heat capacity calculated with the HFK parameters provided by Blanc et al. (2012), instead of the heat capacity given by Rogers and Pitzer (1981), while still using their specific interaction parameters. At $10{ }^{\circ} \mathrm{C}$, the fit with experimental data is not good for $\mathrm{Na}_{2} \mathrm{SO}_{4}$

concentrations above 0.25 mol. $\mathrm{kg}^{-1}$ (Fig. 2a). This is consistent with the fact that the model of Rogers and Pitzer (1981) is valid for temperatures greater than $25^{\circ} \mathrm{C}$. At higher temperatures, the match between experimental and calculated data is satisfactory.

In order to extend the set of interaction parameters of $\mathrm{Na}_{2} \mathrm{SO}_{4}$ over the entire temperature and salinity ranges, a new set of interaction parameters was determined using experimental data for the heat capacity and the osmotic coefficient taken from studies reported in Table 3 . The new set of interaction parameters is reported in Table 4 and the heat capacity calculated with 
this new set of interaction parameters is plotted in Fig. 2 and the osmotic coefficient is plotted in Fig. 3 at various temperatures ranging between 0 and $170^{\circ} \mathrm{C}$. Data are represented up to saturation with respect to $\mathrm{Na}_{2} \mathrm{SO}_{4}(\mathrm{~s})$. The $\mathrm{a}_{\mathrm{i}}$ parameters were optimized using simultaneously osmotic coefficient and heat capacity data.

There are no significant differences between the standard volume of $\mathrm{Na}_{2} \mathrm{SO}_{4}$ given by Phutela and Pitzer (1986b) and the one calculated with the HKF equations. Therefore, the density values calculated with the interaction parameters of Phutela and Pitzer (1986b) and the standard volume calculated with the HKF parameters describe very satisfactorily the experimental values (Fig. 4) without further parameter optimization. The errors obtained on the experimental data are $0.068 \%, 0.049 \%$ and $0.153 \%$ at 15,55 and $95{ }^{\circ} \mathrm{C}$ respectively.

To describe all of the $\mathrm{Na}_{2} \mathrm{SO}_{4}-\mathrm{H}_{2} \mathrm{O}$ binary system's thermodynamic properties, new solubility products of mirabilite $\left(\mathrm{Na}_{2} \mathrm{SO}_{4} \cdot 10 \mathrm{H}_{2} \mathrm{O}\right)$ and thenardite $\left(\mathrm{Na}_{2} \mathrm{SO}_{4}\right)$ had to be revised in consistency with our new set of interaction parameters (Fig. 5). Experimental solubility data have been reported by several authors and compiled by Linke (1965). The constants used for the calculation of solubility products according to temperature are given in Table 5.

\subsubsection{The $\mathrm{MgSO}_{4}-\mathrm{H}_{2} \mathrm{O}$ binary system}

Fig. 6 presents both the standard heat capacity and the volume of $\mathrm{MgSO}_{4}$ optimized by Phutela and Pitzer (1986a, 1986b) and calculated with the HKF equations (Helgeson et al. (1981); Johnson et al. (1992)). The values of the standard heat capacity obtained by Phutela and Pitzer (1986a) are slightly greater than the values calculated with the HKF equations. For the standard volume, there is no significant difference.

The heat capacity and the density of $\mathrm{MgSO}_{4}$ solutions were then calculated using the interaction parameters of Phutela and Pitzer (1986a, 1986b) and the calculation of standard 
properties implemented in PhreeSCALE. The interaction parameters (Y) described by Phutela and Pitzer (1986a) were therefore converted to the PhreeSCALE format for comparison (Eq. (7)). For the heat capacity, there was a discrepancy between the calculated and experimental values above $50{ }^{\circ} \mathrm{C}$ (Fig. 7). Therefore, a new set of interaction parameters was determined using heat capacity and osmotic coefficient data. The new interaction parameters are given in Table 6. The results are plotted in Fig. 7 for the heat capacity (solid lines) and in Fig. 8 for the osmotic coefficient. Data are represented up to saturation with respect to $\mathrm{MgSO}_{4}(\mathrm{~s})$.

For the density, Fig. 9 shows that the parameters of Phutela and Pitzer (1986b) coupled with the standard properties calculated with the HKF equations are in agreement with experimental data. The error obtained on the experimental data is $0.327 \%, 0.438 \%$ and $0.907 \%$ at 5,55 and $95{ }^{\circ} \mathrm{C}$ respectively. The solubility of $\mathrm{MgSO}_{4}$ in $\mathrm{H}_{2} \mathrm{O}$ is plotted in Fig. 10 and can be compared with the experimental data reported by Linke (1965). The solubility curves were calculated using the solubility products of $\mathrm{MgSO}_{4} \cdot \mathrm{nH}_{2} \mathrm{O}[\mathrm{n}=7,6$ or 1$]$ given in Table 5 .

\subsubsection{The $\mathrm{Na}_{2} \mathrm{SO}_{4}-\mathrm{MgSO}_{4}-\mathrm{H}_{2} \mathrm{O}$ ternary system}

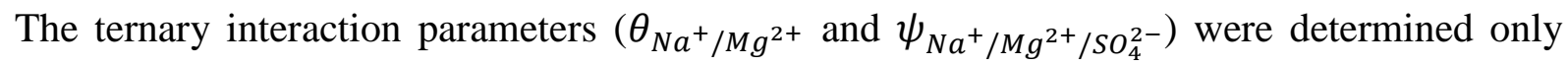
from the solubility data. A value of 0.07 was chosen for the parameter $\theta_{\mathrm{Na}^{+} / \mathrm{Mg}^{2+}}$ (Harvie et al., 1984). Pabalan and Pitzer (1987) used this value to determine solubility in the $\mathrm{NaCl}$ $\mathrm{MgCl}_{2}-\mathrm{H}_{2} \mathrm{O}$ ternary system. In order to ensure the consistency of the database, we used their

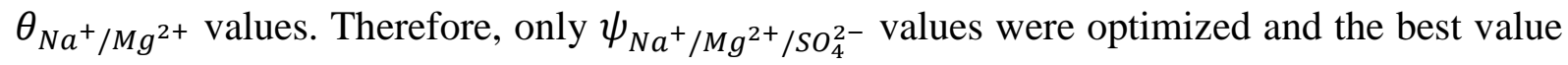
was -0.0181193 . The solubility constant of the double salts $\left(\mathrm{Na}_{2} \mathrm{SO}_{4} \cdot \mathrm{MgSO}_{4} \cdot 4 \mathrm{H}_{2} \mathrm{O}\right.$, $\mathrm{Na}_{2} \mathrm{SO}_{4} \cdot \mathrm{MgSO}_{4} \cdot 2.5 \mathrm{H}_{2} \mathrm{O}$ or $3 \mathrm{Na}_{2} \mathrm{SO}_{4} \cdot \mathrm{MgSO}_{4}$ ) were also optimized (Table 5). The solubility diagram in the $\mathrm{Na}_{2} \mathrm{SO}_{4}-\mathrm{MgSO}_{4}-\mathrm{H}_{2} \mathrm{O}$ system was plotted at various temperatures (Fig. 11). Solubility data were accurately described up to $75{ }^{\circ} \mathrm{C}$. At $100{ }^{\circ} \mathrm{C}$, however, the invariant points were not correctly described. This discrepancy can be explained by our use of 
temperature-independent ternary interaction parameters in order to be coherent with the authors cited above. 


\section{Conclusion}

New equations were derived in the framework of the Pitzer formalism to describe some apparent properties of aqueous solutions, namely enthalpy, heat capacity and density. These equations can theoretically apply to any complex aqueous system since they explicitly include all of the thermal and volumetric specific interactions parameters related to binary and ternary interactions between cations, anions and neutral species. These equations are obtained by temperature or pressure derivatives of the excess Gibbs free energy and are included in the geochemical code PHREEQC V3 (Parkhurst and Appelo, 2013). A modified version of this new code, PhreeSCALE, was successfully tested on the $\mathrm{Na}_{2} \mathrm{SO}_{4}-\mathrm{H}_{2} \mathrm{O}, \mathrm{MgSO}_{4}-\mathrm{H}_{2} \mathrm{O}$ binary systems and on more complex systems (Na-K-Cl-SO ${ }_{4}-\mathrm{H}_{2} \mathrm{O}$ and $\mathrm{Na}-\mathrm{K}-\mathrm{Ca}-\mathrm{Mg}-\mathrm{Cl}-\mathrm{SO}_{4}-\mathrm{HCO}_{3^{-}}$ $\left.\mathrm{H}_{2} \mathrm{O}\right)$ for which interaction parameters $\left(\mathrm{Y}, \mathrm{Y}^{\mathrm{L}}, \mathrm{Y}^{\mathrm{J}}\right.$ and $\left.\mathrm{Y}^{\mathrm{V}}\right)$ and standard properties $\left(C_{p, i}^{0}\right.$ and $V_{i}^{\circ}$ of any compound $i$ ) are available in the literature. In this study, the standard properties were calculated directly using PhreeSCALE, which uses the HKF equations (Helgeson et al., 1981) instead of the standard properties fitted. Consequently, it can be necessary to reoptimize interaction parameters, which is the case of $\mathrm{Na}_{2} \mathrm{SO}_{4}-\mathrm{H}_{2} \mathrm{O}$ and $\mathrm{MgSO}_{4}-\mathrm{H}_{2} \mathrm{O}$ binary systems. The methodology described for these systems can be applied to many other electrolyte systems if sufficient experimental data are available to enable full parameterization of the systems.

Finally, the main innovation implemented in PhreeSCALE is the calculation of the heat capacity of aqueous solutions using both the Pitzer and the HKF equations. Calculation of the density is also possible with the same formalisms. If the interaction parameters $\left(\mathrm{Y}\right.$ and $\mathrm{Y}^{\mathrm{V}}$ ) are available PhreeSCALE can be used to calculate directly osmotic coefficient, heat capacity and density; if not they can be optimized by coupling PhreeSCALE and the parameter estimation software PEST (Doherty, 2004). 


\section{Acknowledgements}

This work was funded by BRGM (the French Geological Survey). The authors thank the LABEX Voltaire (ANR-10-LABX-100-01).

\section{References}

Al Ghafri, S., Maitland, G.C., Trusler, J.P.M., 2012. Densities of Aqueous $\mathrm{MgCl}_{2}(\mathrm{aq})$, $\mathrm{CaCl}_{2}$ (aq), $\mathrm{KI}(\mathrm{aq}), \mathrm{NaCl}(\mathrm{aq}), \mathrm{KCl}(\mathrm{aq}), \mathrm{AlCl}_{3}(\mathrm{aq})$, and $(0.964 \mathrm{NaCl}+0.136 \mathrm{KCl})$ (aq) at Temperatures Between (283 and 472) K, Pressures up to $68.5 \mathrm{MPa}$, and Molalities up to $6 \mathrm{~mol} \cdot \mathrm{kg}-1$. Journal of Chemical \& Engineering Data 57, 1288-1304. doi:10.1021/je2013704

Andersson, J.-O., Helander, T., Höglund, L., Shi, P., Sundman, B., 2002. Thermo-Calc \& DICTRA, computational tools for materials science. Calphad 26, 273-312. doi:10.1016/S0364-5916(02)00037-8

Appelo, C.A.J., Parkhurst, D.L., Poste, V.E.A., 2014. Equations for calculating hydrogeochemical reactions of minerals and gases such as $\mathrm{CO} 2$ at high pressures and temperatures. Geochimica et Cosmochimica Acta 125, 49-67. doi: 10.1016/j.gca.2013.10.003

Aqueous Solutions ApS, n.d. AQSOL001 [WWW Document]. URL http://www.phasediagram.dk/

Baabor, J.S., Gilchrist, M.A., Delgado, E.J., 1998. Thermodynamic Properties of Aqueous Sodium Sulfate Solutions at $40^{\circ}$ C. Journal of solution Chemistry 27, 67-72. doi:10.1023/A:1022640612451

Bachu, S., Adams, J.J., 2003. Sequestration of $\mathrm{CO}_{2}$ in geological media in response to climate change: capacity of deep saline aquifers to sequester $\mathrm{CO}_{2}$ in solution. Energy Conversion and Management 44, 3151-3175. doi:10.1016/S0196-8904(03)00101-8

Bhatnagar, O.N., Campbell, A.N., 1981. Osmotic and activity coefficients of sodium sulphate in water from 50 to $150{ }^{\circ} \mathrm{C}$. Canadian Journal of Chemistry 59, 123-126. doi:10.1139/v81-019

Bhatnagar, O.N., Campbell, A.N., 1982. Osmotic and activity coefficients of sodium sulphate in water from 150 to $250{ }^{\circ} \mathrm{C}$. Canadian Journal of Chemistry 60, 1754-1758. doi: $10.1139 / \mathrm{v} 82-240$

Blanc, P., Lassin, A., Piantone, P., 2012. Thermoddem a database devoted to waste minerals [WWW Document]. BRGM (Orléans, Fr.) http://thermoddem.brgm.fr. URL http://thermoddem.brgm.fr

Christov, C., Møller, N., 2004. Chemical equilibrium model of solution behavior and solubility in the $\mathrm{H}-\mathrm{Na}-\mathrm{K}-\mathrm{OH}-\mathrm{Cl}-\mathrm{HSO}_{4}-\mathrm{SO}_{4}-\mathrm{H}_{2} \mathrm{O}$ system to high concentration and temperature. Geochimica et Cosmochimica Acta 68, 1309-1331. doi:10.1016/j.gca.2003.08.017 
Conti, G., Gianni, P., Tiné, M.R., 1986. Heat capacities of aqueous mixed electrolyte solutions at high temperatures. Application of the Pitzer equations to the mixed system K-Na-Cl-SO4. Journal of Solution Chemistry 15, 349-362. doi:10.1007/BF00648889

Conti, G., Gianni, P., Tiné, M.R., 1989. Mixed interaction terms in the use of pitzer equations: application to the heat capacities of the reciprocal system $\mathrm{Na}+/ \mathrm{K}+/ \mathrm{Cl}-/ \mathrm{SO} 42-/ \mathrm{H} 2 \mathrm{O}$ at high temperatures. Thermochimica Acta 145, 61-75. doi:10.1016/0040-6031(89)851263

Doherty, J., 2004. PEST: Model-Independent Parameter Estimation, 5th ed.

Downes, C.J., Pitzer, K.S., 1976. Thermodynamics of electrolytes. Binary mixtures formed from aqueous $\mathrm{NaCl}, \mathrm{Na}_{2} \mathrm{SO}_{4}, \mathrm{CuCl}_{2}$, and $\mathrm{CuSO}_{4}$, at $25^{\circ} \mathrm{C}$. Journal of Solution Chemistry 5, 389-398. doi:10.1007/BF00646413

El Guendouzi, M., Mounir, A., Dinane, A., 2003. Water activity, osmotic and activity coefficients of aqueous solutions of $\mathrm{Li}_{2} \mathrm{SO}_{4}, \mathrm{Na}_{2} \mathrm{SO}_{4}, \mathrm{~K}_{2} \mathrm{SO}_{4},\left(\mathrm{NH}_{4}\right)_{2} \mathrm{SO}_{4}, \mathrm{MgSO}_{4}$, $\mathrm{MnSO}_{4}, \mathrm{NiSO}_{4}, \mathrm{CuSO}_{4}$, and $\mathrm{ZnSO}_{4}$ at $\mathrm{T}=298.15 \mathrm{~K}$. The Journal of Chemical Thermodynamics 35, 209-220. doi:10.1016/S0021-9614(02)00315-4

El Guendouzi, M., Aboufaris, M., 2015. Comparative Study of Sodium Phosphate and Sodium Sulfate in Aqueous Solutions at (298.15 to 353.15) K. Journal of Chemical \& Engineering Data 60, 2308-2319. doi:10.1021/acs.jced.5b00203

Felmy, A.R., Weare, J.H., 1986. The prediction of borate mineral equilibria in natural waters: Application to Searles Lake, California. Geochimica et Cosmochimica Acta 50, 27712783. doi:10.1016/0016-7037(86)90226-7

Harvie, C.E., Møller, N., Weare, J.H., 1984. The prediction of mineral solubilities in natural waters: The $\mathrm{Na}-\mathrm{K}-\mathrm{Mg}-\mathrm{Ca}-\mathrm{H}-\mathrm{Cl}-\mathrm{SO}_{4}-\mathrm{OH}-\mathrm{HCO}_{3}-\mathrm{CO}_{3}-\mathrm{CO}_{2}-\mathrm{H}_{2} \mathrm{O}$ system to high ionic strengths at $25^{\circ} \mathrm{C}$. Geochimica et Cosmochimica Acta 48, 723-751. doi:10.1016/00167037(84)90098-X

Helgeson, H.C., Kirkham, D.H., Flowers, G.C., 1981. Theoretical prediction of the thermodynamic behavior of aqueous electrolytes by high pressures and temperatures; IV, Calculation of activity coefficients, osmotic coefficients, and apparent molal and standard and relative partial molal properties to $600^{\circ} \mathrm{C}$. American Journal of Science 281, 1249-1516. doi:10.2475/ajs.281.10.1249

Hellams, K.L., Paterson, C.S., Prentice, B.H., Taylor, M.J., 1965. Osmotic Properties of Some Aqueous Solutions at $45^{\circ}$ C. Journal of Chemical \& Engineering Data 10, 323-325. doi:10.1021/je60027a006

Holmes, H.., Mesmer, R.., 1986. Isopiestic studies of aqueous solutions at elevated temperatures VIII. The alkali-metal sulfates. The Journal of Chemical Thermodynamics 18, 263-275. doi:10.1016/0021-9614(86)90055-8

Hubert, N., Bouroukba, M., Schuffenecker, L., 1995. Aqueous solution of sodium sulfate. Determination of the dissolution enthalpy at $25,27.5$ and $45^{\circ} \mathrm{C}$. Thermochimica Acta 259, 41-48. doi:10.1016/0040-6031(95)02273-5

Humphries, W.T., Kohrt, C.F., Patterson, C.S., 1968. Osmotic properties of some aqueous electrolytes at 60.deg. Journal of Chemical \& Engineering Data 13, 327-330. doi:10.1021/je60038a008

Johnson, J., Oelkers, E., Helgeson, H., 1992. SUPCRT92: A software package for calculating 
the standard molal thermodynamic properties of minerals, gases, aqueous species, and reactions from 1 to 5000 bar. Computers \& Geosciences 18, 899-947. doi:10.1016/00983004(92)90029-Q

Kobylin, P., Salminen, J., Hultgren, M., 2014. 36. Aqua Module. Outotec 1-49.

Krumgalz, B.S., 2000. Volumetric Ion Interaction Parameters for Single-Solute Aqueous Electrolyte Solutions at Various Temperatures. Journal of Physical and Chemical Reference Data 29, 1123. doi:10.1063/1.1321053

Lach, A., André, L., Lassin, A., Azaroual, M., Serin, J.-P., Cézac, P., 2015. A new Pitzer parameterization for the binary $\mathrm{NaOH}-\mathrm{H} 2 \mathrm{O}$ and ternary $\mathrm{NaOH}-\mathrm{NaCl}-\mathrm{H} 2 \mathrm{O}$ and $\mathrm{NaOH}-$ $\mathrm{LiOH}-\mathrm{H} 2 \mathrm{O}$ systems up to $\mathrm{NaOH}$ solid salt saturation, from 273.15 to $523.15 \mathrm{~K}$ and at saturated vapour pressure. Journal of Solution Chemistry 44, 1424-1451. doi: $10.1007 / \mathrm{s} 10953-015-0357-6$

Likke, S., Bromley, L.A., 1973. Heat capacities of aqueous sodium chloride, potassium chloride, magnesium chloride, magnesium sulfate, and sodium sulfate solutions between 80.deg. and 200.deg. Journal of Chemical \& Engineering Data 18, 189-195. doi:10.1021/je60057a027

Lin, S., Yip, N.Y., Elimelech, M., 2014. Direct contact membrane distillation with heat recovery: Thermodynamic insights from module scale modeling. Journal of Membrane Science 453, 498-515. doi:10.1016/j.memsci.2013.11.016

Linke, W., 1965. Solubilities inorganic and metal-organic compounds Volume II, 4th ed. , 4th edn., American Chemical Society.

Magalhães, M. , Königsberger, E., May, P.M., Hefter, G., 2002. Heat capacities of concentrated aqueous solutions of sodium sulfate, sodium carbonate, and sodium hydroxide at 25 C. Journal of Chemical \& Engineering Data 47, 590-598. doi:10.1021/je010314h

Møller, N., 1988. The prediction of mineral solubilities in natural waters: A chemical equilibrium model for the $\mathrm{Na}-\mathrm{Ca}-\mathrm{Cl}-\mathrm{SO} 4-\mathrm{H} 2 \mathrm{O}$ system, to high temperature and concentration. Geochimica et Cosmochimica Acta 52, 821-837. doi:10.1016/00167037(88)90354-7

Monnin, C., 1994. Density calculation and concentration scale conversions for natural waters. Computers \& Geosciences 20, 1435-1445. doi: 10.1016/0098-3004(94)90103-1

Monnin, C., 1989. An ion interaction model for the volumetric properties of natural waters: Density of the solution and partial molal volumes of electrolytes to high concentrations at $25^{\circ} \mathrm{C}$. Geochimica et Cosmochimica Acta 53, 1177-1188. doi:10.1016/00167037(89)90055-0

Moore, J.T., Humphries, W.T., Patterson, C.S., 1972. Isopiestic studies of some aqueous electrolyte solutions at 80.deg. Journal of Chemical \& Engineering Data 17, 180-182. doi:10.1021/je60053a035

Pabalan, R.T., Pitzer, K.S., 1988. Apparent molar heat capacity and other thermodynamic properties of aqueous potassium chloride solutions to high temperatures and pressures. Journal of Chemical \& Engineering Data 33, 354-362. doi:10.1021/je00053a037

Pabalan, R.T., Pitzer, K.S., 1987. Thermodynamics of concentrated electrolyte mixtures and the prediction of mineral solubilities to high temperatures for mixtures in the system NaK-Mg-Cl-SO4-OH-H2O. Geochimica et Cosmochimica Acta 51, 2429-2443. 
doi:10.1016/0016-7037(87)90295-X

Parkhurst, D.L., Appelo, C.A.J., 2013. Description of Input and Examples for PHREEQC Version 3-A Computer Program for Speciation, Batch-Reaction, One-Dimensional Transport, and Inverse Geochemical Calculations.

Patterson, C.S., Gilpatrick, L.O., Soldano, B.A., 1960. 545. The osmotic behaviour of representative aqueous salt solutions at $100^{\circ} \mathrm{C}$. Journal of the Chemical Society 2730. doi:10.1039/jr9600002730

Perron, G., Desnoyers, J.E., Millero, F.J., 1975. Apparent Molal Volumes and Heat Capacities of some Sulfates and Carbonates in Water at $25^{\circ} \mathrm{C}$. Canadian Journal of Chemistry 53, 1134-1138. doi:10.1139/v75-157

Phutela, R.C., Pitzer, K.S., 1986a. Heat capacity and other thermodynamic properties of aqueous magnesium sulfate to $473 \mathrm{~K}$. The Journal of Physical Chemistry 90, 895-901. doi:10.1021/j100277a037

Phutela, R.C., Pitzer, K.S., 1986b. Densities and apparent molar volumes of aqueous magnesium sulfate and sodium sulfate to $473 \mathrm{~K}$ and 100 bar. Journal of Chemical \& Engineering Data 31, 320-327. doi:10.1021/je00045a018

Pitzer, K.S., 1991. Activity coefficients in electrolyte solutions, 2nd ed. CRC Press, Boca Raton.

Platford, R.F., 1973. Osmotic coefficients of aqueous solutions of seven compounds at 0.deg. Journal of Chemical \& Engineering Data 18, 215-217. doi:10.1021/je60057a017

Rard, J.A., Clegg, S.L., Palmer, D.A., 2000. Isopiestic Determination of the Osmotic Coefficients of $\mathrm{Na} 2 \mathrm{SO} 4(\mathrm{aq})$ at 25 and $50^{\circ} \mathrm{C}$, and Representation with Ion-Interaction (Pitzer) and Mole Fraction Thermodynamic Models. Journal of Solution Chemistry 29, 1-49. doi:10.1023/A:1005182316790

Rard, J.A., Miller, D.G., 1981. Isopiestic determination of the Osmotic coefficients of aqueous sodium sulfate, magnesium sulfate, and sodium sulfate-magnesium sulfate at 25 .degree.C. Journal of Chemical \& Engineering Data 26, 33-38. doi:10.1021/je00023a013

Robinson, R.A., Wilson, J.M., Stokes, R.H., 1941. The Activity Coefficients of Lithium, Sodium and Potassium Sulfate and Sodium Thiosulfate at $25^{\circ}$ from Isopiestic Vapor Pressure Measurements. Journal of the American Chemical Society 63, 1011-1013. doi:10.1021/ja01849a034

Rogers, P., Pitzer, K., 1981. High-temperature thermodynamic properties of aqueous sodium sulfate solutions. The Journal of Physical Chemistry 85, 2886-2895. doi:10.1021/j150620a008

Saluja, P.P.S., Jobe, D.J., LeBlanc, J.C., Lemire, R.J., 1995. Apparent Molar Heat Capacities and Volumes of Mixed Electrolytes: $[\mathrm{NaCl}(\mathrm{aq})+\mathrm{CaCl} 2(\mathrm{aq})],[\mathrm{NaCl}(\mathrm{aq})+\mathrm{MgCl} 2(\mathrm{aq})]$, and $[\mathrm{CaCl} 2(\mathrm{aq})+\mathrm{MgCl} 2(\mathrm{aq})]$. Journal of Chemical \& Engineering Data 40, 398-406. doi:10.1021/je00018a007

Schröder, E., Thomauske, K., Schmalzbauer, J., Herberger, S., Gebert, C., Velevska, M., 2015. Design and test of a new flow calorimeter for online detection of geothermal water heat capacity. Geothermics 53, 202-212. doi:10.1016/j.geothermics.2014.06.001

Soldano, B.A., Patterson, C.S., 1962. 175. Osmotic behaviour of aqueous salt solutions at elevated temperatures. Part II. Journal of the Chemical Society 937. 
doi:10.1039/jr9620000937

Tanger, J.C., Helgeson, H.C., 1988. Calculation of the thermodynamic and transport properties of aqueous species at high pressures and temperatures; revised equations of state for the standard partial molal properties of ions and electrolytes. American Journal of Science 288, 19-98. doi:10.2475/ajs.288.1.19

Thomsen, K., 1997. Aqueous Electrolytes Model Parameters and Process Simulation. Technical University of Denmark.

Wang, P., Anderko, A., Young, R.D., 2002. A speciation-based model for mixed-solvent electrolyte systems. Fluid Phase Equilibria 203, 141-176. doi:10.1016/S03783812(02)00178-4

Zaytsev, I.D., Aseyev, G.G., 1992. Properties of Aqueous Solutions of Electrolytes. CRC Press. 


\section{Figure captions}

Figure 1 - Comparison of the standard properties of $\mathrm{Na}_{2} \mathrm{SO}_{4}$ computed by Rogers and Pitzer (1981) for the heat capacity and Phutela and Pitzer (1986b) for the volume (symbols) with the values computed with HKF parameters (lines): a) the standard heat capacity, b) the standard volume at saturation pressure.

Figure 2 - Calculated (dotted line for HKF + interaction parameters of Rogers and Pitzer (1981), lines for HKF + interaction parameters optimized in this study) and experimental (close circle or open shape) heat capacity for the $\mathrm{Na}_{2} \mathrm{SO}_{4}-\mathrm{H}_{2} \mathrm{O}$ system as a function of molalities of $\mathrm{Na}_{2} \mathrm{SO}_{4}$ at: a) $10^{\circ} \mathrm{C}$, b) $25^{\circ} \mathrm{C}$, c) $80^{\circ} \mathrm{C}$ and d) $177.26^{\circ} \mathrm{C}$ at saturation pressure

Figure 3 - Calculated (lines) and experimental (open symbol) osmotic coefficient for the $\mathrm{Na}_{2} \mathrm{SO}_{4}-\mathrm{H}_{2} \mathrm{O}$ system (after optimization) as a function of molalities of $\mathrm{Na}_{2} \mathrm{SO}_{4}$. For convenience of representation the curves were shifted 0.1 for $25^{\circ} \mathrm{C}, 0.2$ for $40^{\circ} \mathrm{C}$ and so on.

Figure 4 - Calculated (lines) and experimental (open symbol) density for the $\mathrm{Na}_{2} \mathrm{SO}_{4}-\mathrm{H}_{2} \mathrm{O}$ system as a function of molalities of $\mathrm{Na}_{2} \mathrm{SO}_{4}$ at $15^{\circ} \mathrm{C}, 55^{\circ} \mathrm{C}$ and $95^{\circ} \mathrm{C}$ at saturation pressure

Figure 5 - Calculated (lines) and experimental (open symbols) solubility of mirabilite $\left(\mathrm{Na}_{2} \mathrm{SO}_{4} \cdot 10 \mathrm{H}_{2} \mathrm{O}\right)$ and thenardite $\left(\mathrm{Na}_{2} \mathrm{SO}_{4}\right)$ as a function of temperature in the $\mathrm{Na}_{2} \mathrm{SO}_{4}-\mathrm{H}_{2} \mathrm{O}$ binary system.

Figure 6 - Comparison of the standard properties of $\mathrm{MgSO}_{4}$ computed by Phutela and Pitzer (1986a) for the heat capacity and Phutela and Pitzer (1986b) for the volume (symbols) with the values computed with HKF parameters (lines): a) the standard heat capacity, b) the standard volume at saturation pressure. 
Figure 7 - Calculated (dotted line for HKF + interaction parameters of Phutela and Pitzer (1986a), lines for HKF + interaction parameters optimized in this study) and experimental (symbols) heat capacity for the $\mathrm{MgSO}_{4}-\mathrm{H}_{2} \mathrm{O}$ system as a function of molalities of $\mathrm{Na}_{2} \mathrm{SO}_{4}$ at: a) $15^{\circ} \mathrm{C}$, b) $25^{\circ} \mathrm{C}$, c) $80^{\circ} \mathrm{C}$ and d) $120^{\circ} \mathrm{C}$ at saturation pressure

Figure 8 - Calculated (lines) and experimental (open symbol) osmotic coefficient for the $\mathrm{MgSO}_{4}-\mathrm{H}_{2} \mathrm{O}$ system (after optimization) as a function of molalities of $\mathrm{MgSO}_{4}$. For convenience of representation the curves were shifted 0.2 for $25^{\circ} \mathrm{C}, 0.7$ for $99.6^{\circ} \mathrm{C}, 0.9$ for $109.99^{\circ} \mathrm{C}$ and 1.1 for $121.1^{\circ} \mathrm{C}$.

Figure 9 - Calculated (lines) and experimental (open symbol) density for the $\mathrm{MgSO}_{4}-\mathrm{H}_{2} \mathrm{O}$ system as a function of molalities of $\mathrm{MgSO}_{4}$ at $5^{\circ} \mathrm{C}, 55^{\circ} \mathrm{C}$ and $95^{\circ} \mathrm{C}$.

Figure 10 - Calculated (lines) and experimental (open symbols) solubility of epsomite $\left(\mathrm{MgSO}_{4} \cdot 7 \mathrm{H}_{2} \mathrm{O}\right)$, hexahydrite $\left(\mathrm{MgSO}_{4} \cdot 6 \mathrm{H}_{2} \mathrm{O}\right)$ and kieserite $\left(\mathrm{MgSO}_{4} \cdot \mathrm{H}_{2} \mathrm{O}\right)$ as a function of temperature in the $\mathrm{MgSO}_{4}-\mathrm{H}_{2} \mathrm{O}$ binary system.

Figure 11 - Calculated (lines) and experimental (open symbols) solubility in the $\mathrm{MgSO}_{4}$ $\mathrm{Na}_{2} \mathrm{SO}_{4}-\mathrm{H}_{2} \mathrm{O}$ system at a) $25^{\circ} \mathrm{C}$, b) $50^{\circ} \mathrm{C}$, c) $75^{\circ} \mathrm{C}$ and d) $100^{\circ} \mathrm{C}$. 
a)

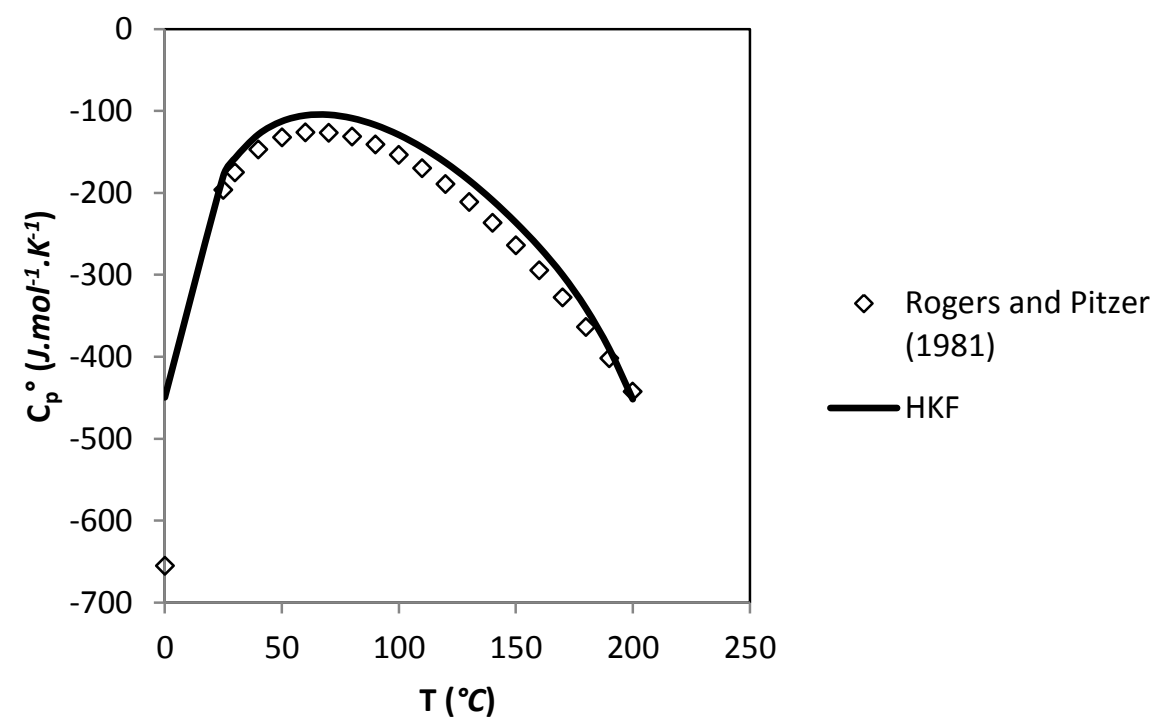

b)

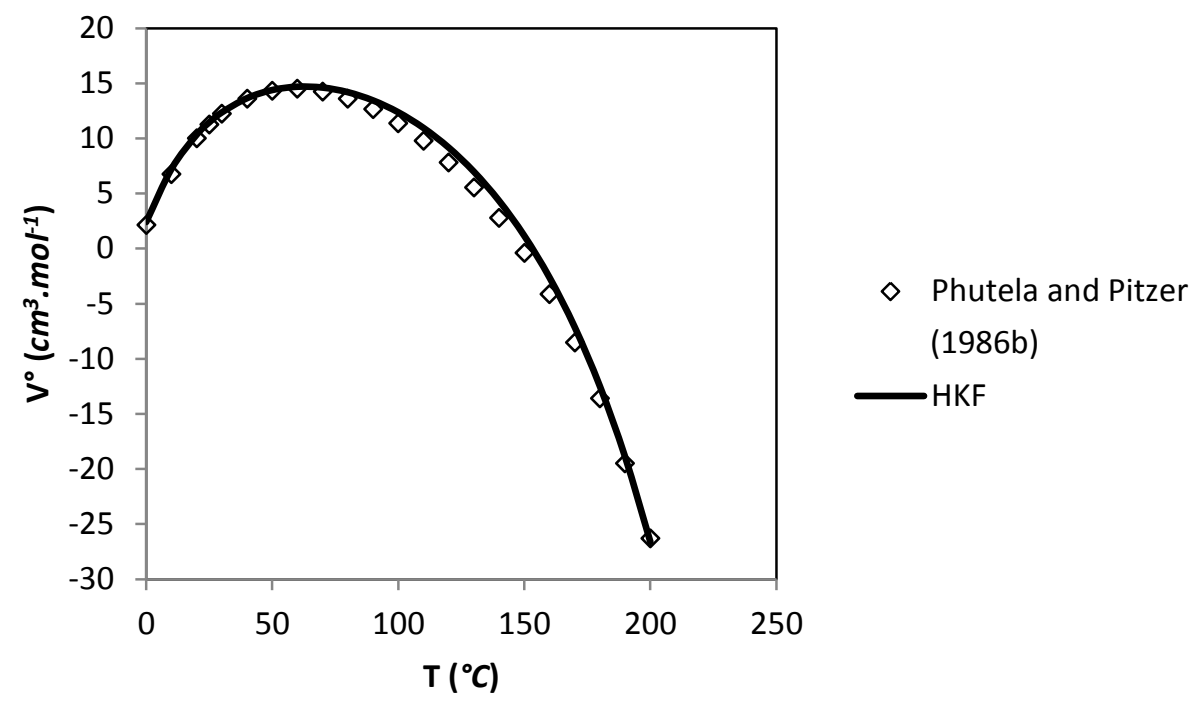

Fig. 1 
a)

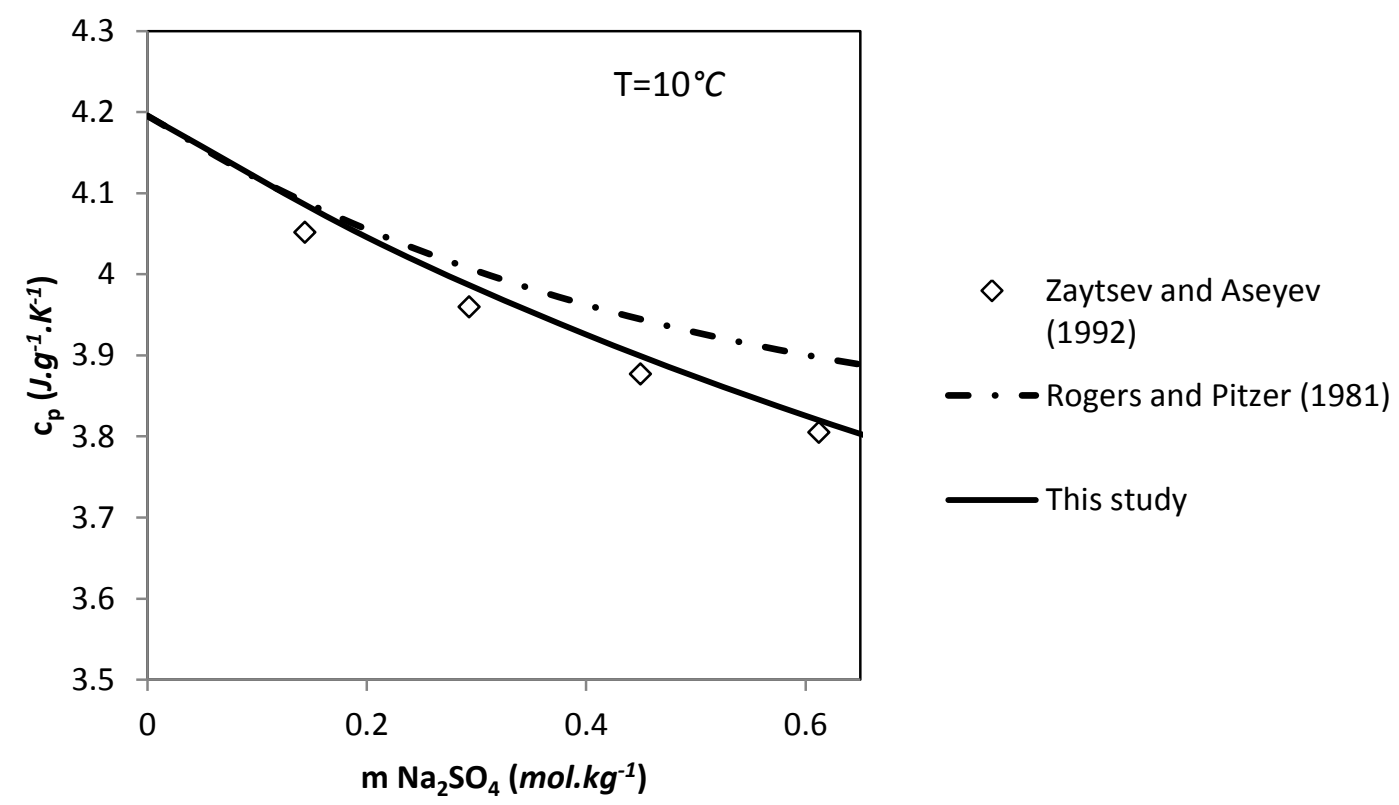

b)

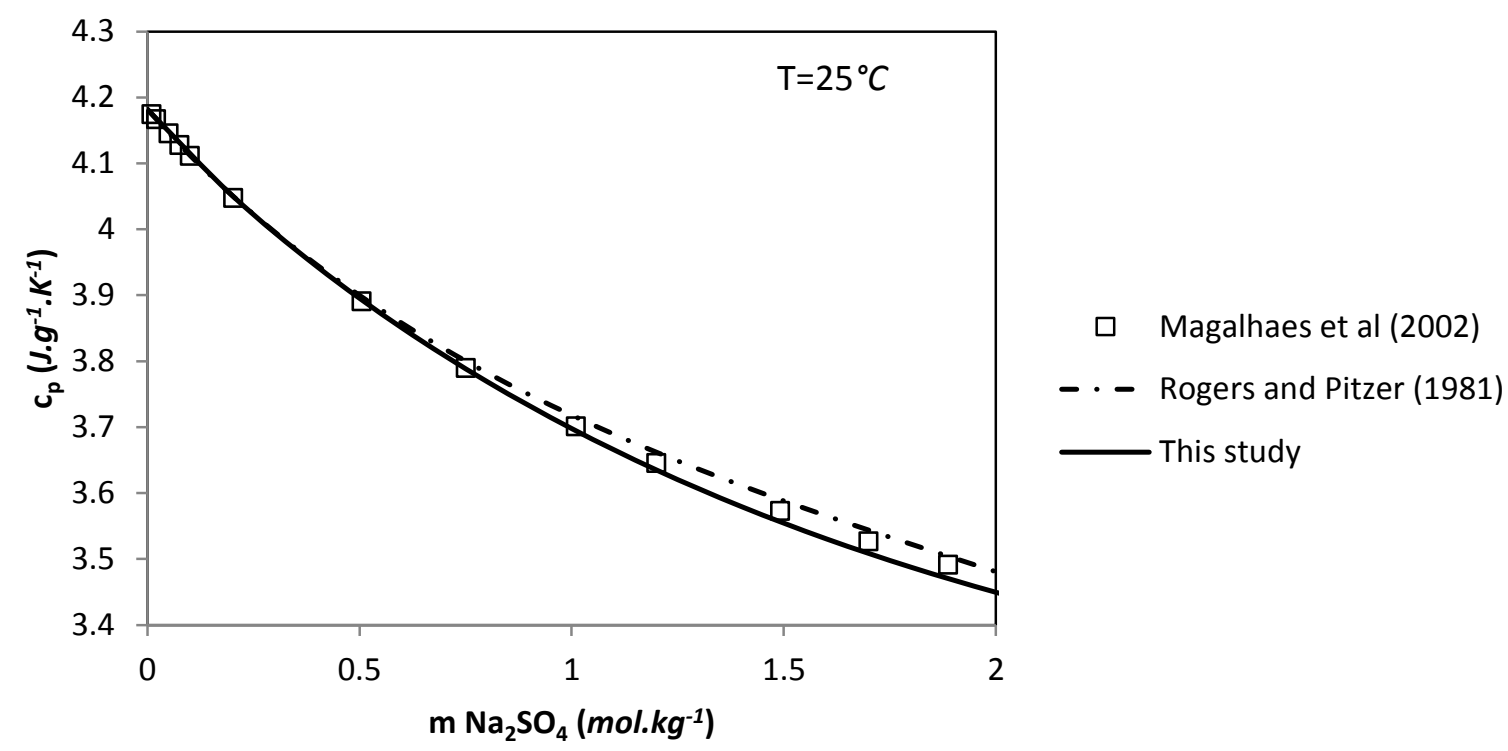

c) 


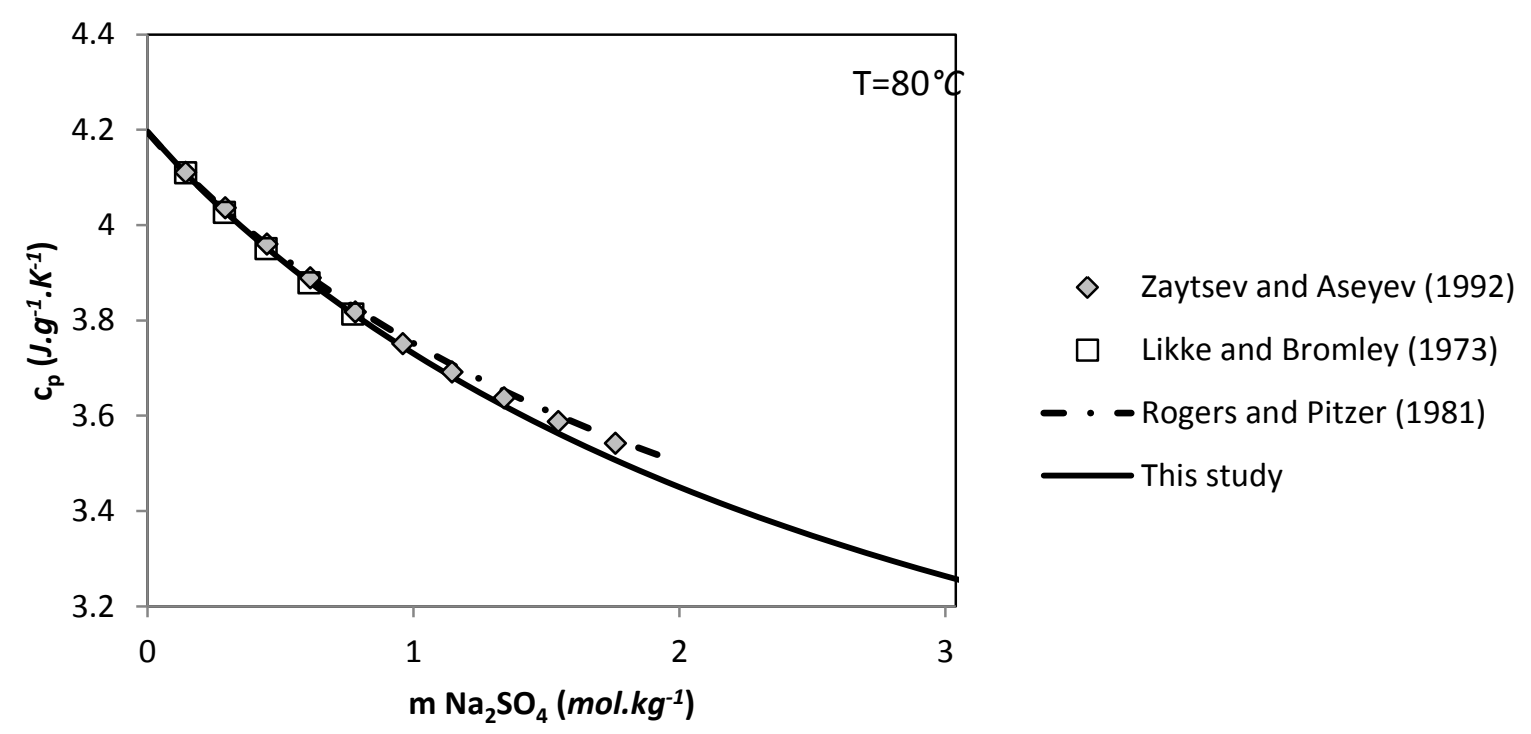

d)

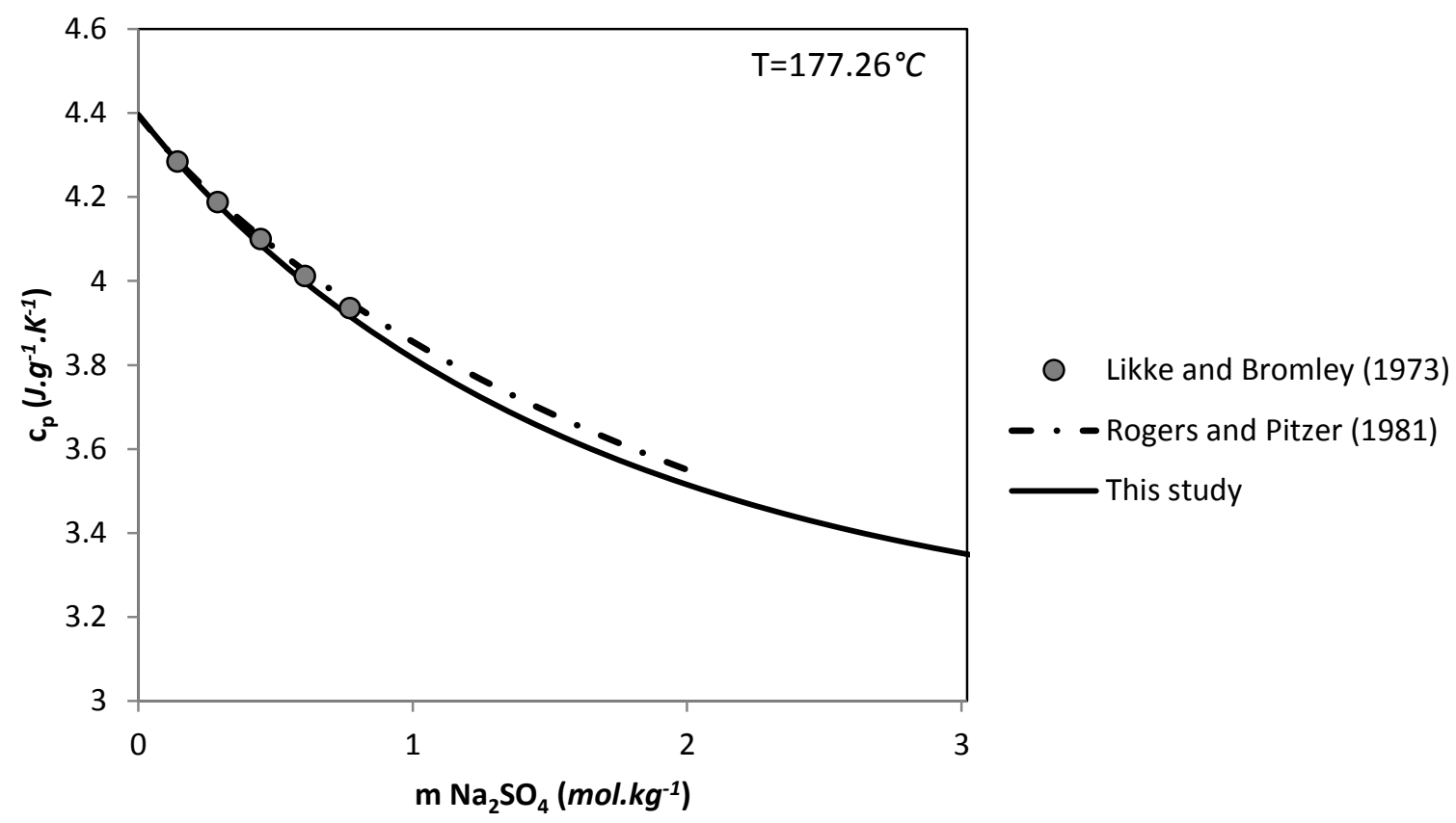

Fig. 2 


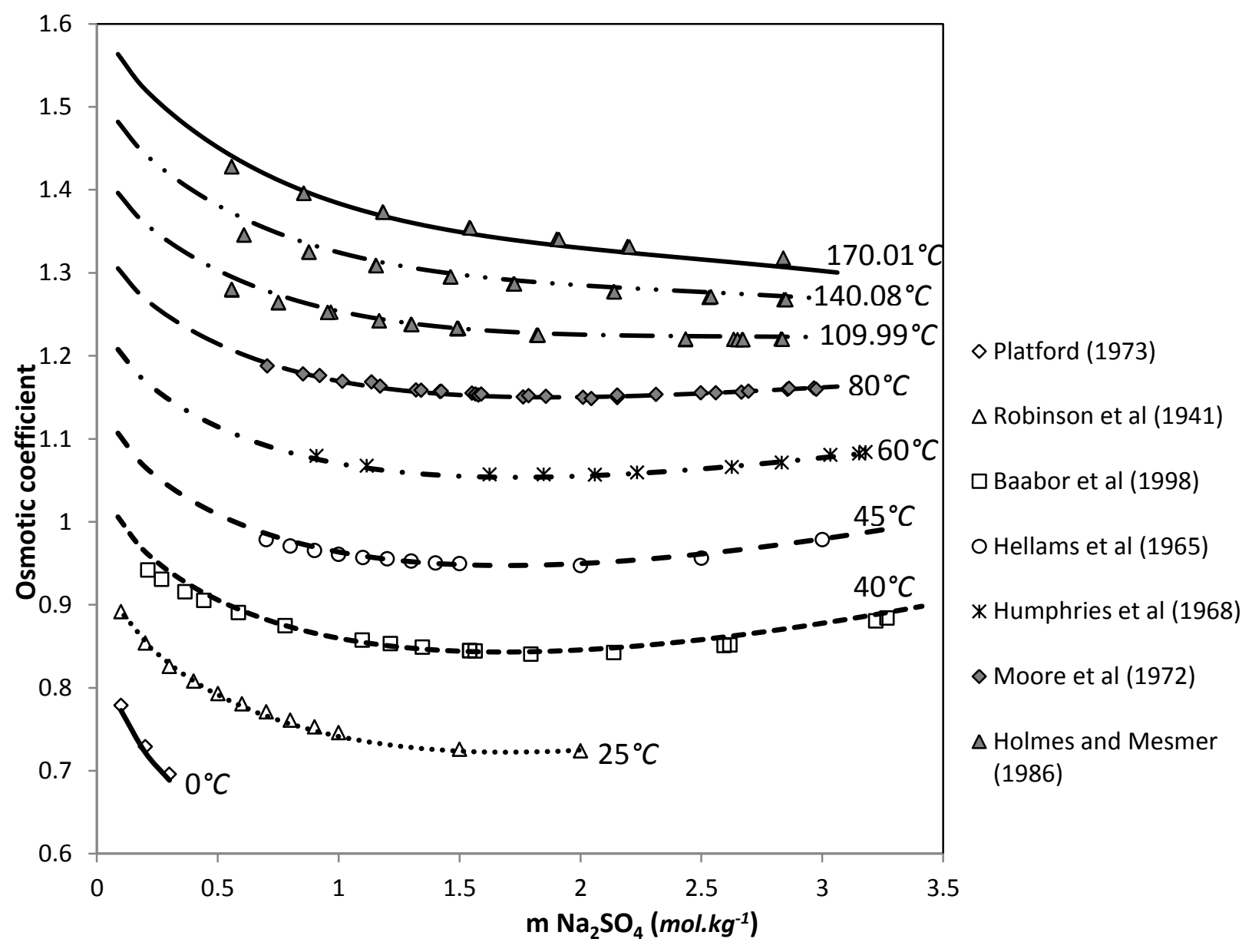

Fig. 3 


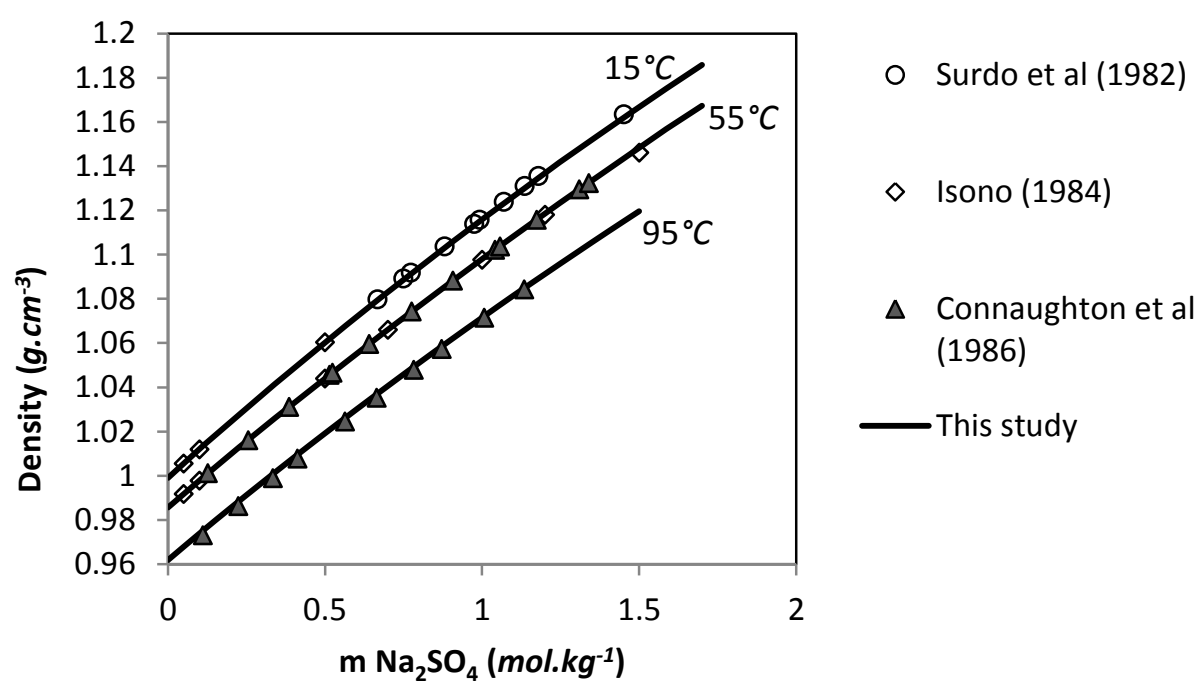

Fig. 4 


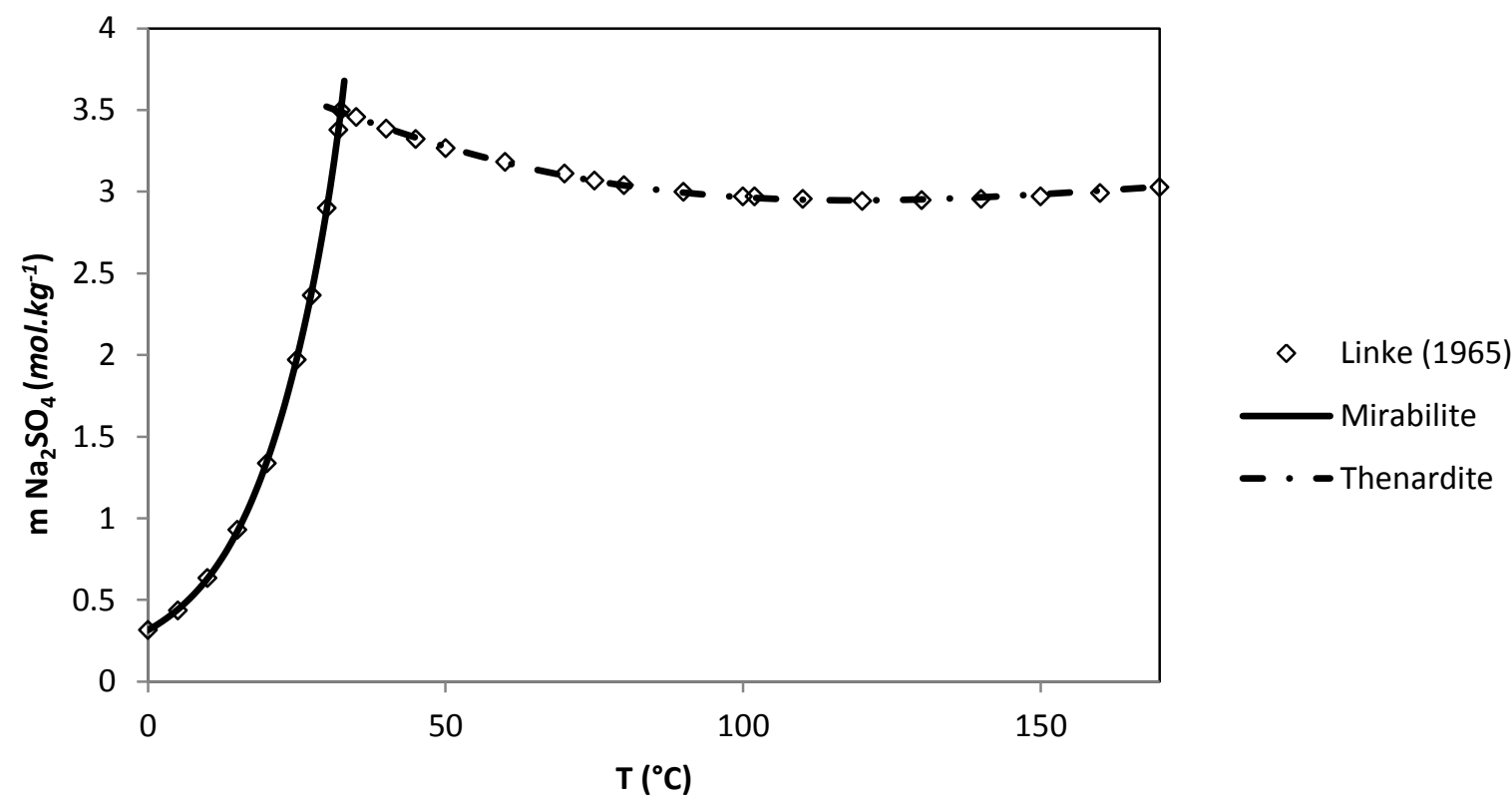

Fig. 5 
a)

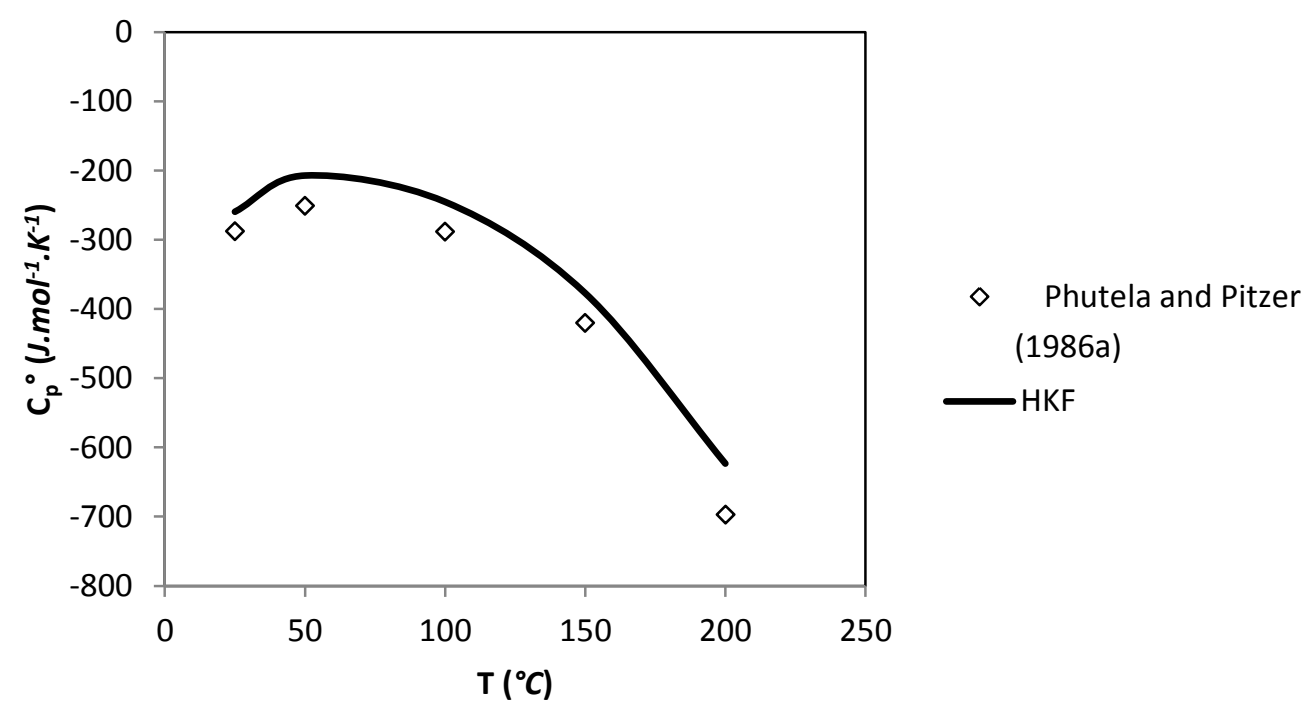

b)

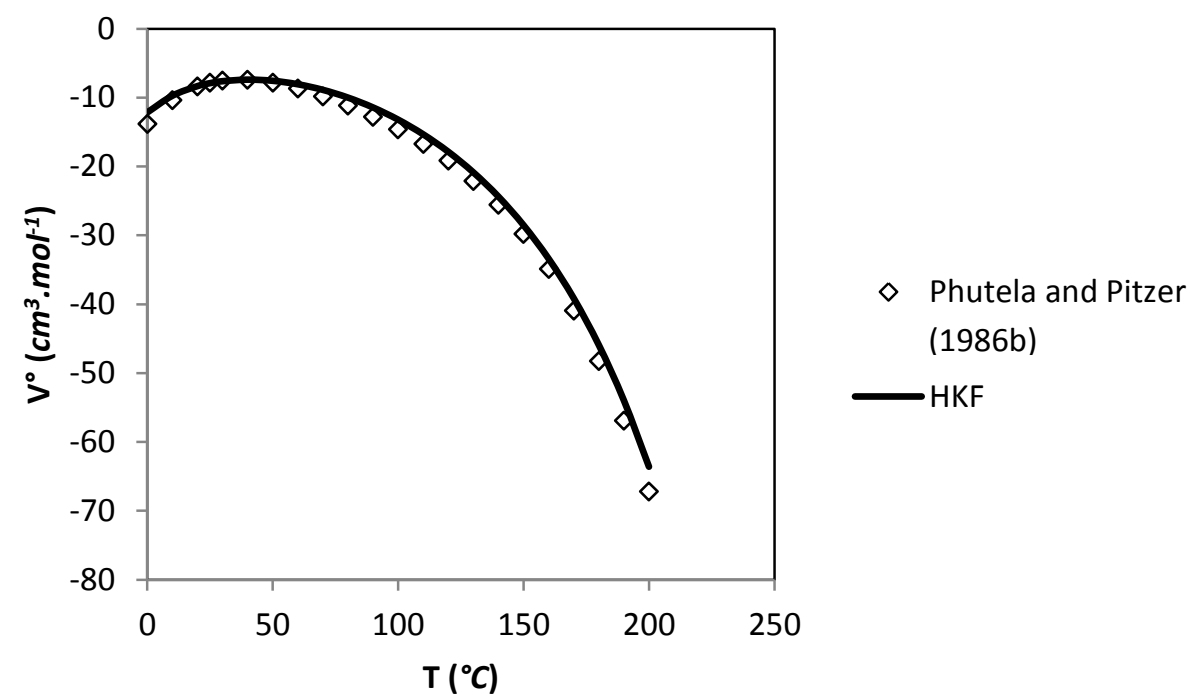

Fig. 6 
a)

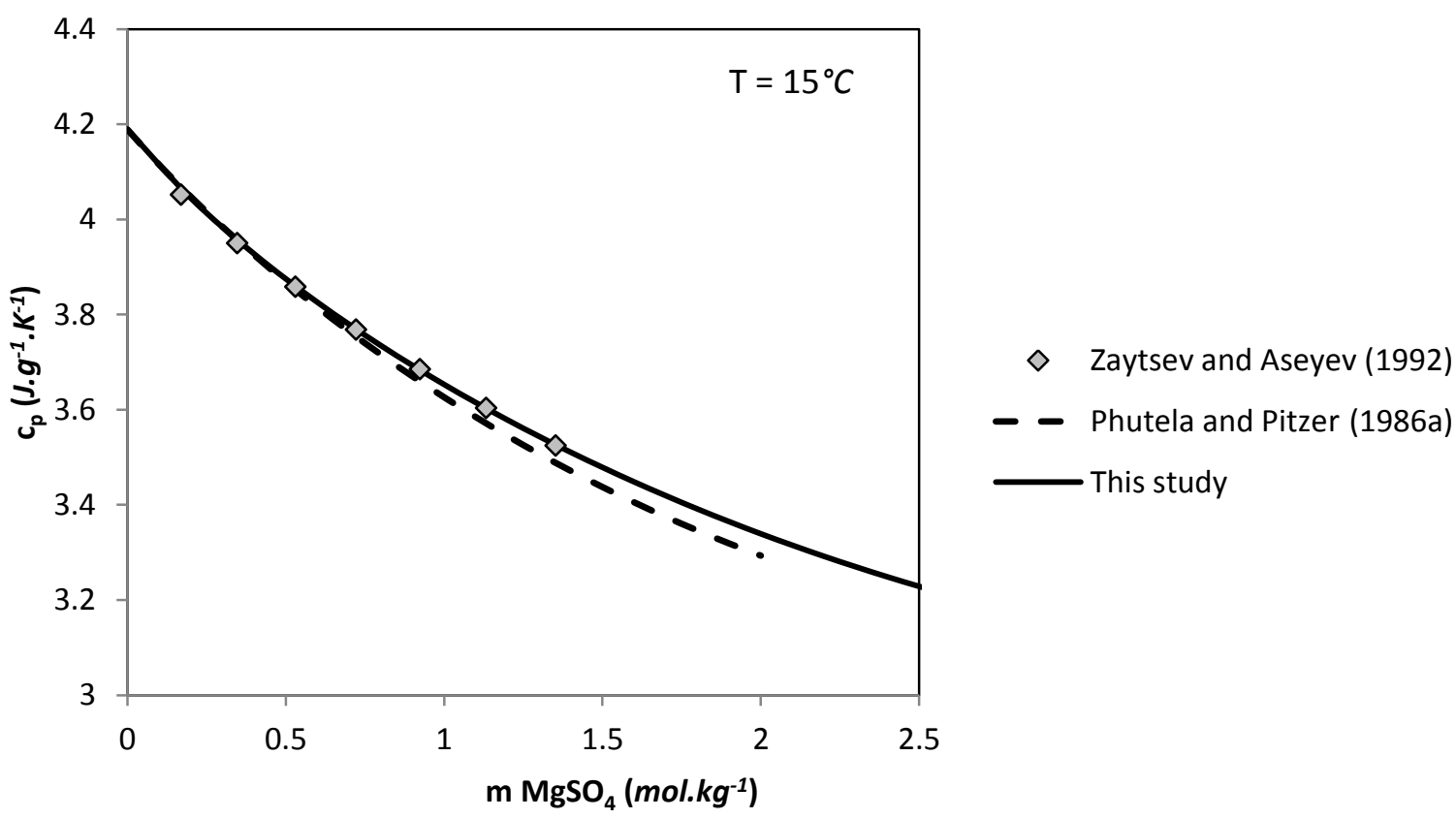

b)

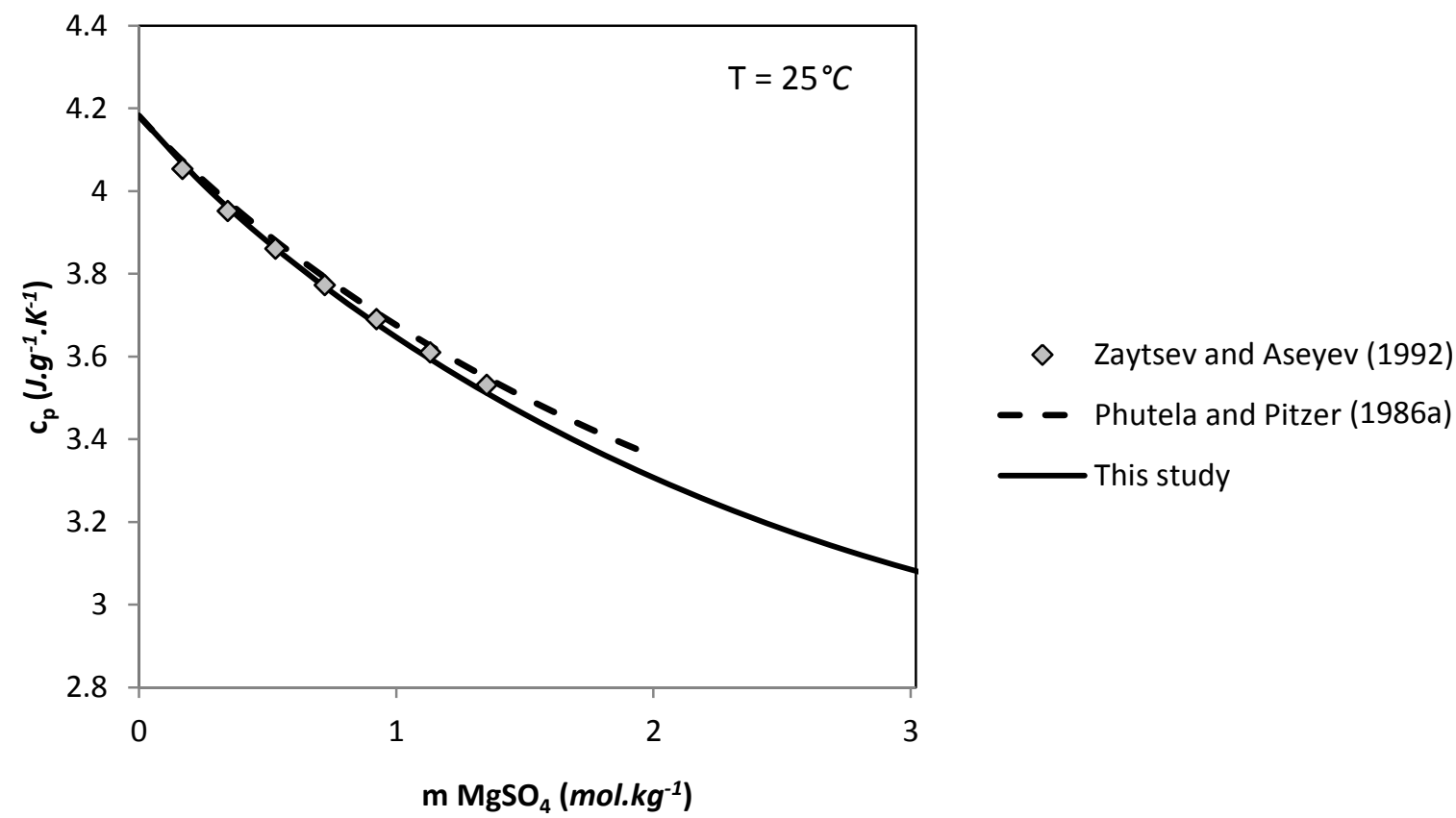

c) 


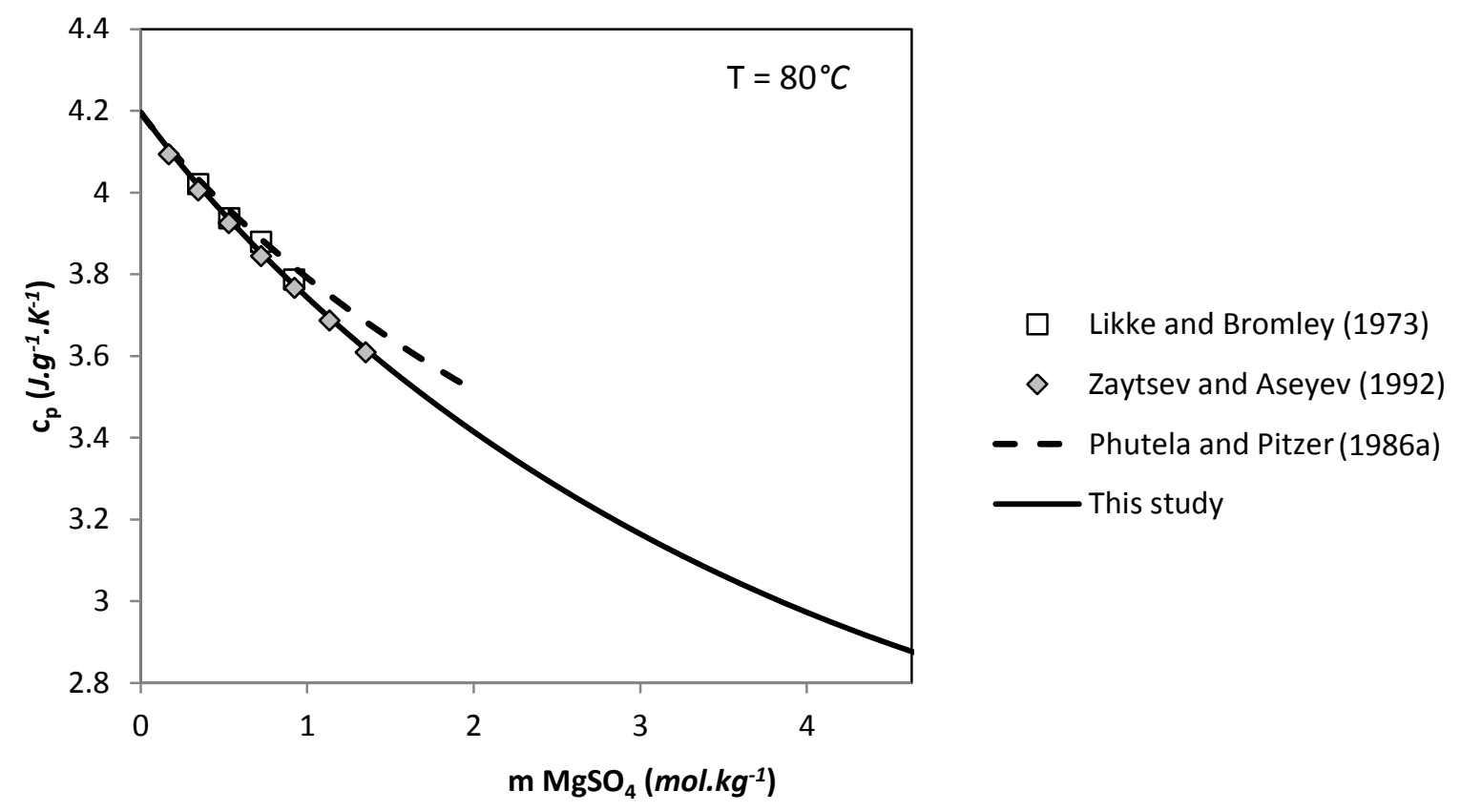

d)

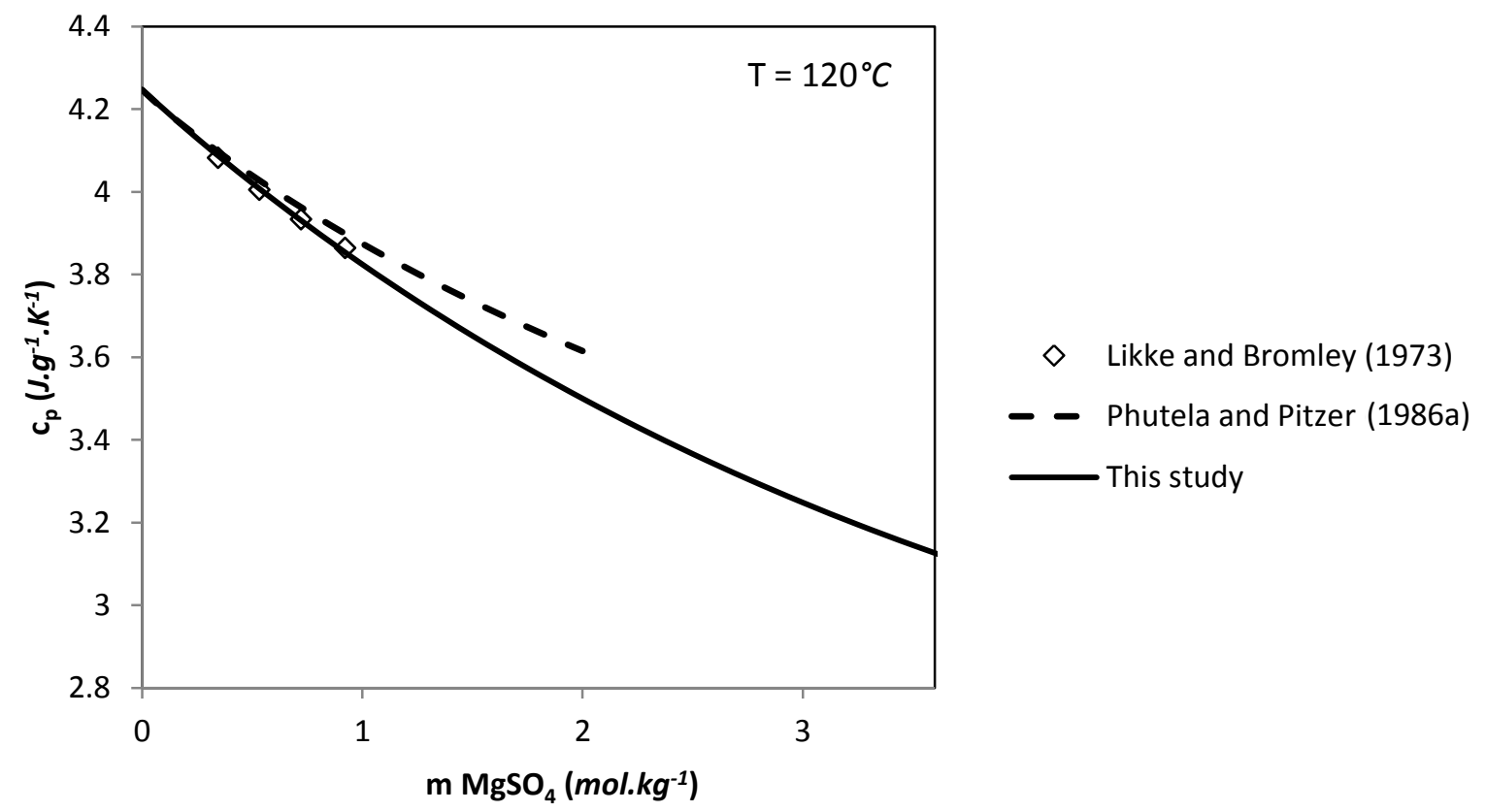

Fig. 7 


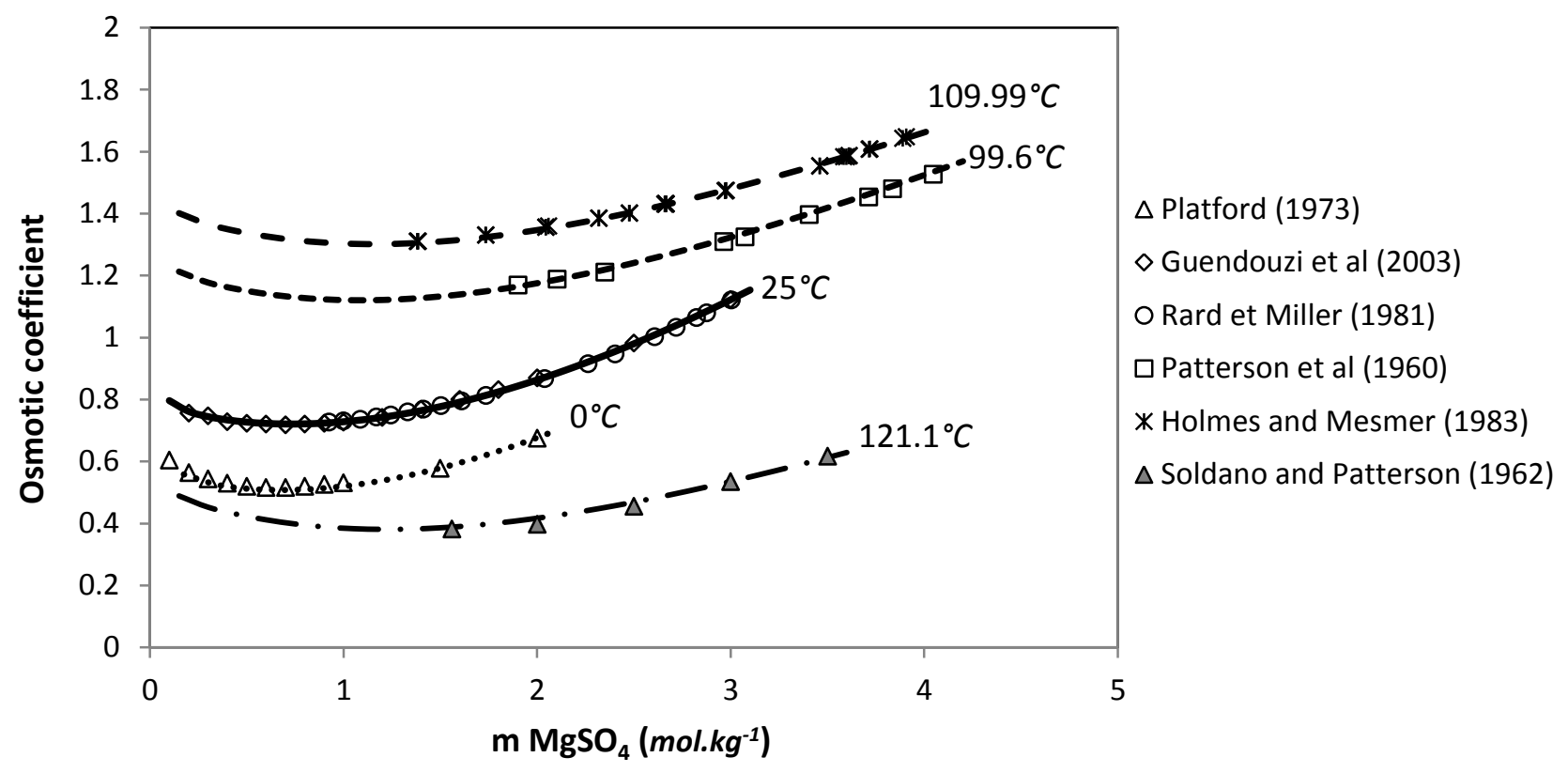

Fig. 8 


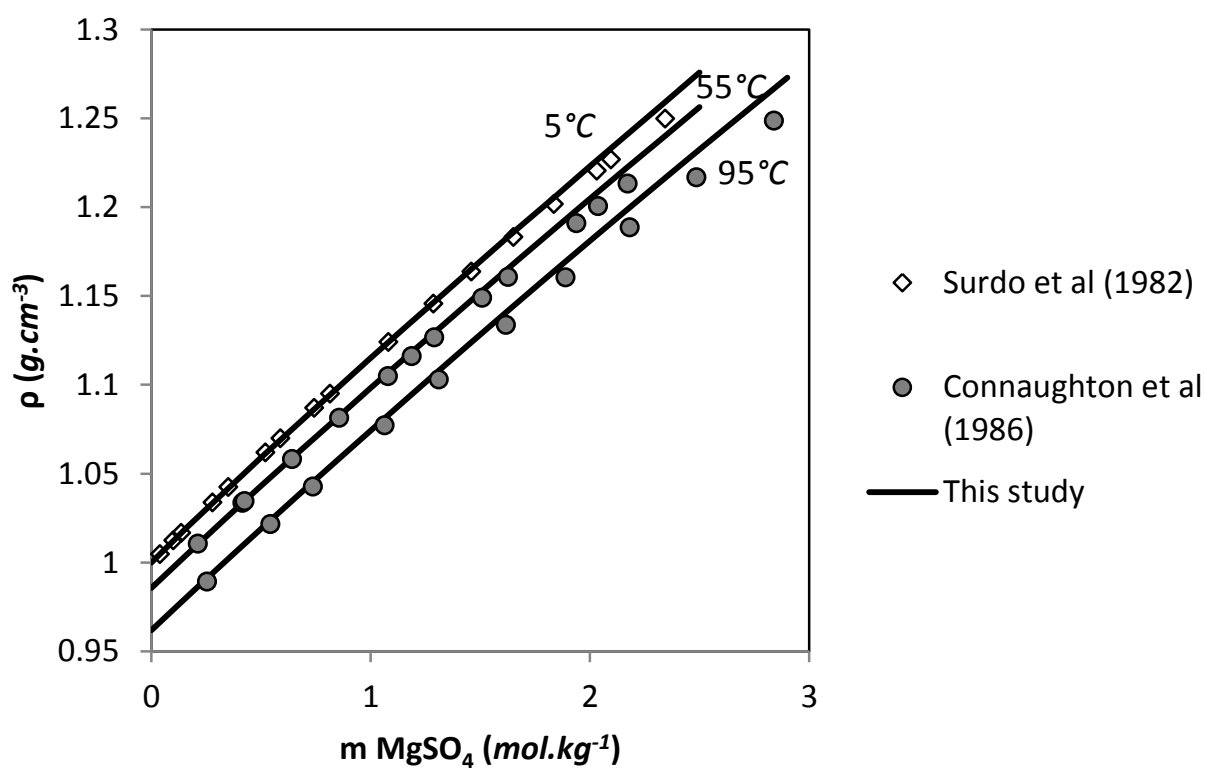

Fig. 9 


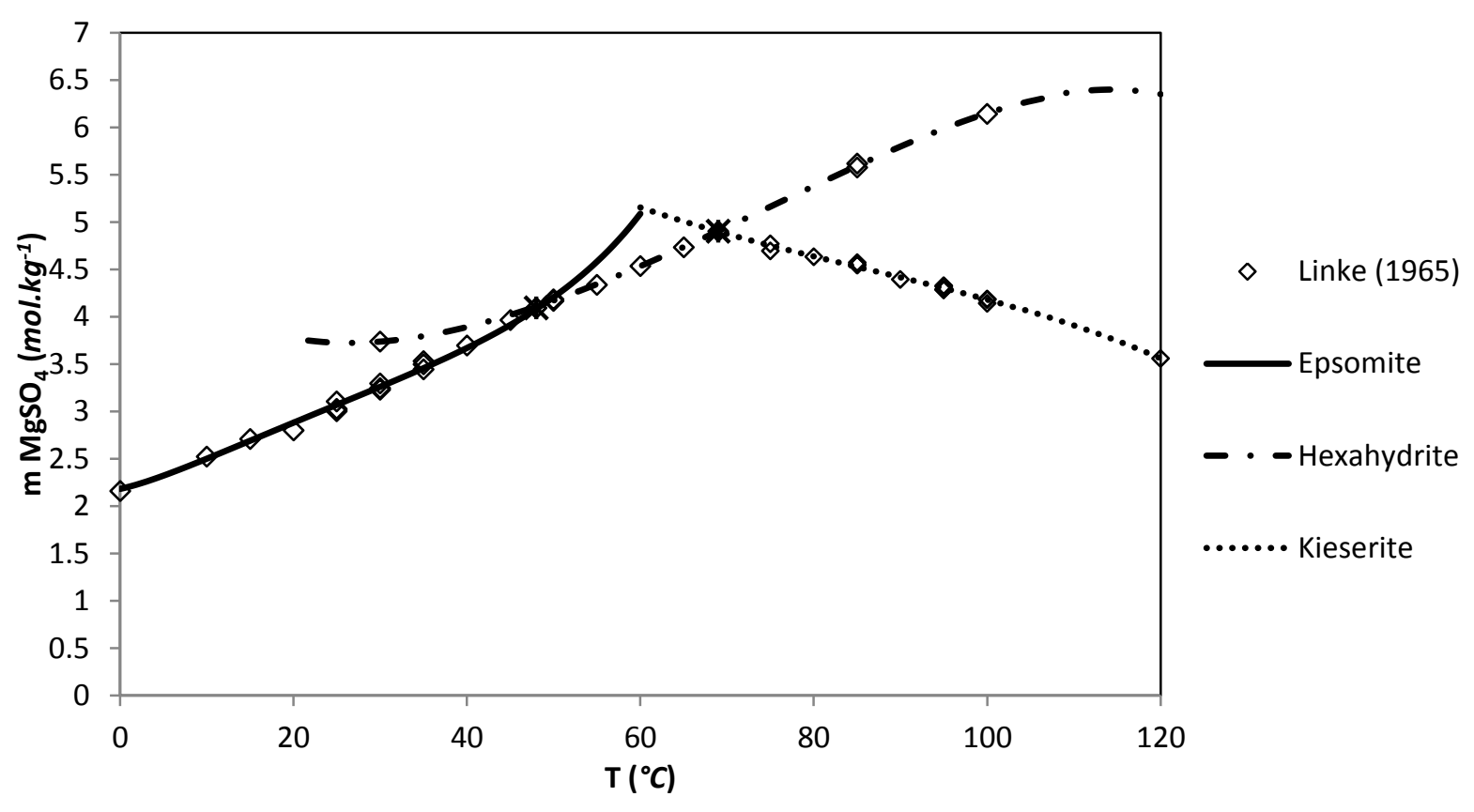

Fig. 10 
a)

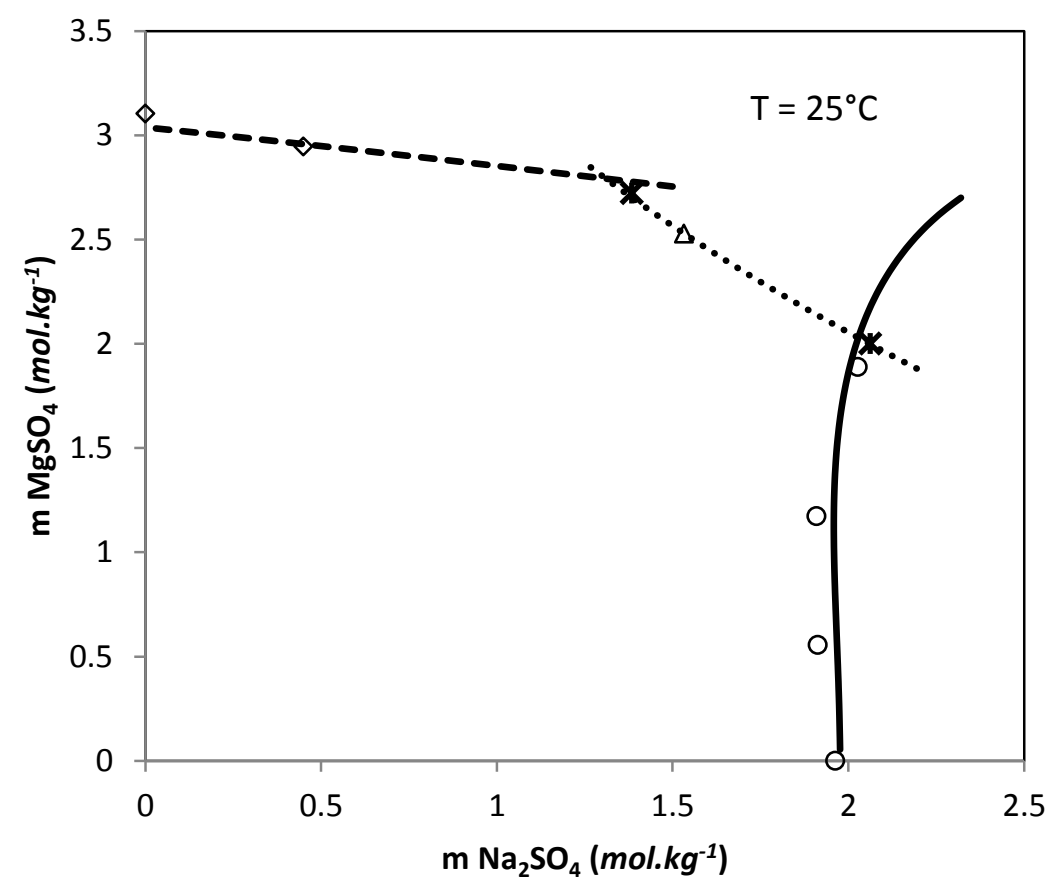

Symbols : Linke (1965)

- Mirabilite

....... Na2SO4.MgSO4.4H2O

-_- Epsomite

b)

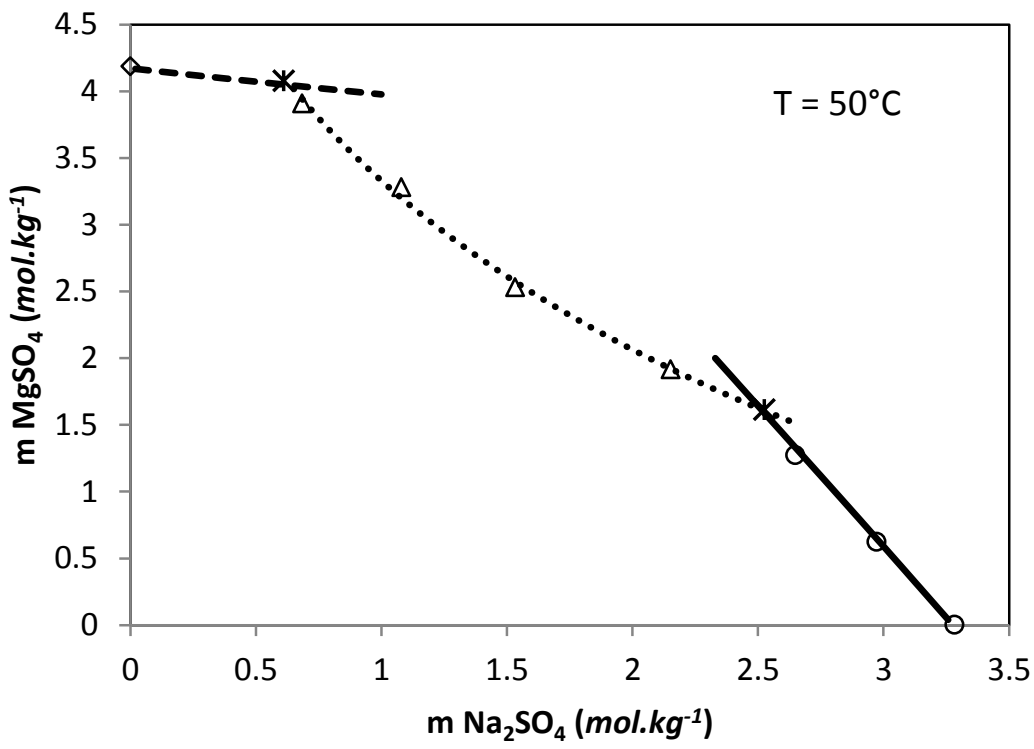

Symbols: Linke (1965)

-Thenardite

...... Na2SO4.MgSO4.4H2O

- - - Hexahydrite

c) 


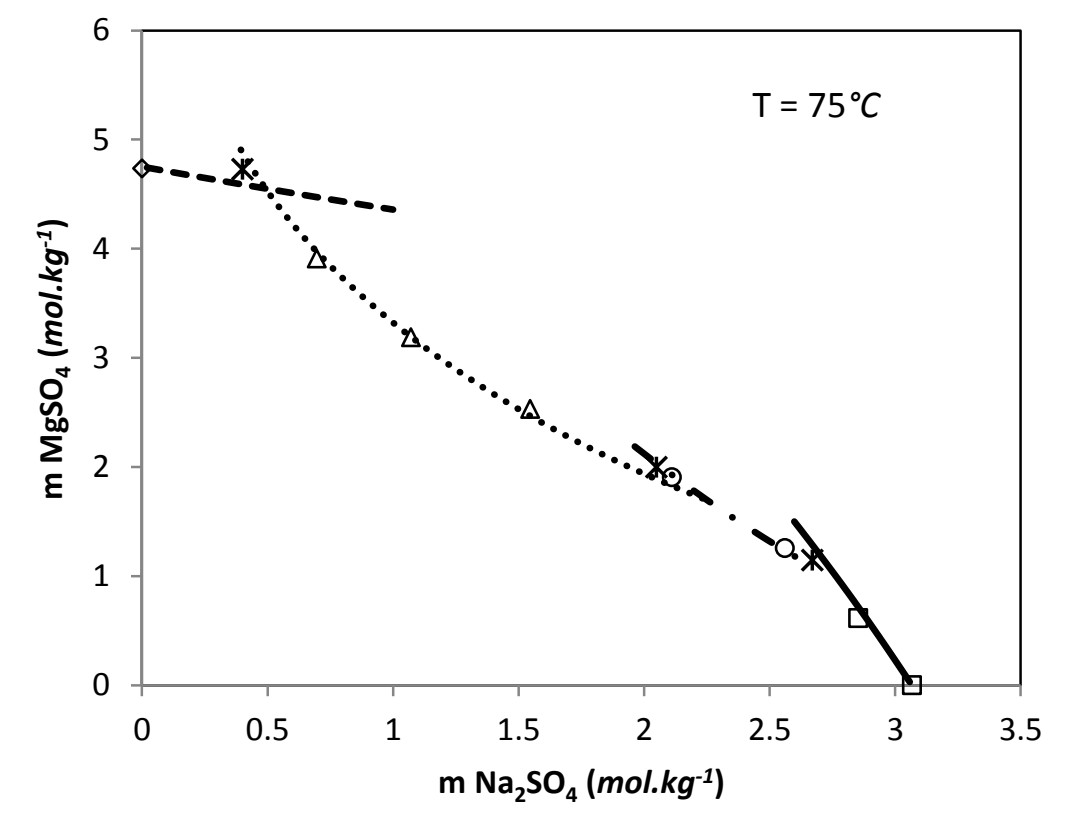

Symbols: Linke (1965)

Thenardite

...... Na2SO4.MgSO4.2.5H2O

- - -3Na2SO4.MgSO4

-----Kieserite

d)

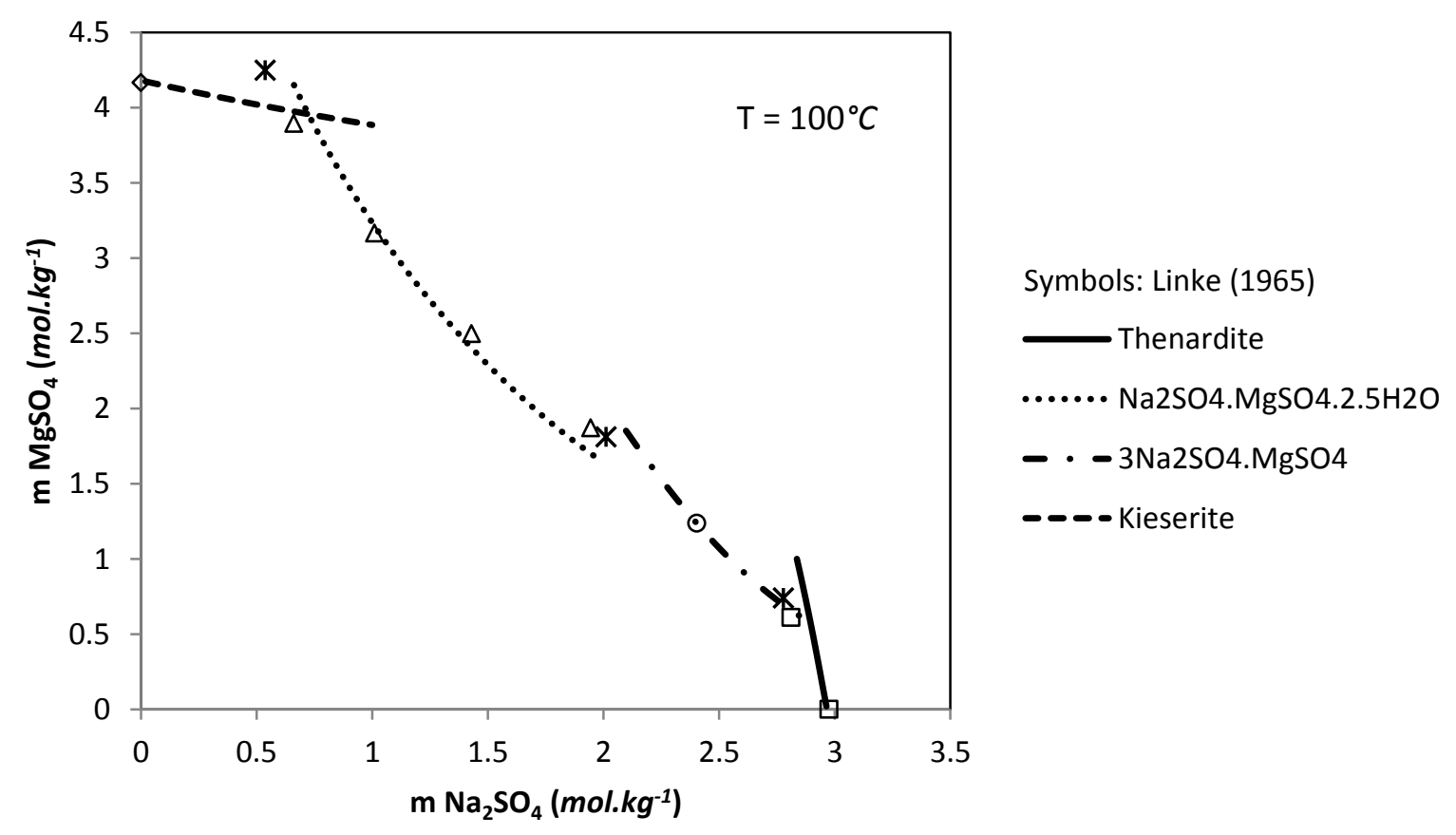

Fig. 11 
Tables

2 
Table 1 . The absolute average relative deviation for the different systems tested

\begin{tabular}{|c|c|c|}
\hline Keywords & Explanations & Model used \\
\hline ENTHALAPP & The apparent relative molar enthalpy of solution $\left(L_{\phi}\right)$ & Eq. (6) \\
\hline \multirow[b]{2}{*}{ CPSTAN(“ $i ”)$} & dard partial molar heat capacity of the aqueous species $i$ & \\
\hline & dilution $\left(C_{p, i}^{0}\right)$ & HKF model \\
\hline CPAPP & The apparent molar heat capacity of the solution $\left(C_{p, \phi}\right)$ & Eq. (15) \\
\hline \multirow[t]{2}{*}{ CPSOL } & The mass heat capacity of the aqueous solution $\left(c_{p}\right)$ & Eq. (18) \\
\hline & andard partial molar volume of the aqueous species $i$ at $\mathrm{i}$ & \\
\hline VSTAN(“i”) & dilution $\left(V_{i}^{\circ}\right)$ & HKF model \\
\hline VAPP & The apparent molar volume of solution $\left(V_{\phi}\right)$ & Eq. (24) \\
\hline DENSOL & The density of the aqueous solution, $\rho$ & Eq. (30) \\
\hline
\end{tabular}


Table 2. The absolute average relative deviation for the different systems tested

\begin{tabular}{|c|c|c|c|c|c|c|}
\hline Systems & Ref. & Parameters used & $\begin{array}{c}\mathbf{T} \\
{ }^{\circ} \mathrm{C}\end{array}$ & Pressure & Data & $\Delta_{A A D}(\%)$ \\
\hline $\mathrm{Na}_{2} \mathrm{SO}_{4}-\mathrm{H}_{2} \mathrm{O}$ & Rogers and Pitzer, 1981 & $\overline{C_{p 2}^{\circ}}, \beta^{(0)}, \beta^{(1)}$ and $C^{\phi}$ & $25-200$ & $\begin{array}{c}1 \text { bar or } \\
\text { saturated } \\
\text { vapor } \\
\text { pressure }\end{array}$ & $\begin{array}{l}C_{p, \phi} \\
L_{\phi} \\
\phi\end{array}$ & $\begin{array}{l}0.362 \\
0.495 \\
0.0392\end{array}$ \\
\hline $\mathrm{MgSO}_{4}-\mathrm{H}_{2} \mathrm{O}$ & Phutela and Pitzer, 1986a & $\overline{C_{p 2}^{\circ}}, \beta^{(0)}, \beta^{(1)}, \beta^{(2)}$ and $C^{\phi}$ & $25-200$ & 20 bar & $\begin{array}{l}C_{p, \phi} \\
L_{\phi} \\
\phi\end{array}$ & $\begin{array}{l}1.955 \\
0.0970 \\
0.118\end{array}$ \\
\hline $\mathrm{Na}-\mathrm{K}-\mathrm{Cl}-\mathrm{SO}_{4}-\mathrm{H}_{2} \mathrm{O}$ & $\begin{array}{l}\text { Conti et al., } 1986 \\
\text { Conti et al., } 1989\end{array}$ & $\begin{array}{c}\overline{C_{p 2}^{\circ}}, \beta^{(0)}, \beta^{(1)} \text { and } C^{\phi} \\
+\theta_{C l^{-} / S O_{4}^{-2}}\end{array}$ & $60-220$ & $\begin{array}{l}\text { vapor } \\
\text { pressure }\end{array}$ & $c_{p}$ & $\begin{array}{l}0.415 \\
0.252\end{array}$ \\
\hline $\mathrm{Na}-\mathrm{K}-\mathrm{Ca}-\mathrm{Mg}-\mathrm{Cl}-\mathrm{SO}_{4}-\mathrm{HCO}_{3}-\mathrm{H}_{2} \mathrm{O}$ & Monnin, 1989 & $\overline{V_{2}^{\circ}}, \beta^{(0) \mathrm{V}}, \beta^{(1) \mathrm{V}}, \beta^{(2) \mathrm{V}}$ and $C^{\phi V}$ & 25 & 1 bar & $\rho$ & 0.133 \\
\hline
\end{tabular}


Table 3. Experimental data used for the optimization of $\mathrm{Na}_{2} \mathrm{SO}_{4}-\mathrm{H}_{2} \mathrm{O}$ binary system at saturation pressure

\begin{tabular}{|c|c|c|c|c|}
\hline Type of data & $\mathbf{T}\left({ }^{\circ} \mathrm{C}\right)$ & m $\left(\right.$ mol.kg $\left.{ }^{-1}\right)$ & Experimental error & Ref. \\
\hline \multirow{10}{*}{ Osmotic coefficient } & 25 & $0.1-4$ & & Robinson et al., 1941 \\
\hline & 45 & $0.76-3.45$ & & Hellams et al., 1965 \\
\hline & 80 & $0.7-3$ & & Moore et al., 1972 \\
\hline & 0 & $0.1-1.5$ & & Platford, 1973 \\
\hline & 25 & $0.2-1.2$ & & Downes and Pitzer, 1976 \\
\hline & $50-250$ & $0.29-3.2$ & & Bhatnagar and Campbell, 1982, 1981 \\
\hline & $109.99-225.04$ & $0.5-3$ & & Holmes and Mesmer, 1986 \\
\hline & 40 & $0.2-3.26$ & & Baabor et al., 1998 \\
\hline & 25 & $0.1-3$ & & El Guendouzi et al., 2003 \\
\hline & $25 ; 50$ & $0.1-3.7$ & & Rard et al., 2000 \\
\hline Heat capacity & $0-90$ & $0.14-1.76$ & - & Zaytsev and Aseyev, 1992 \\
\hline
\end{tabular}


9 Table 4. Values of the fitting constants for the interaction parameters of $\mathrm{Na}_{2} \mathrm{SO}_{4}-\mathrm{H}_{2} \mathrm{O}$ binary system (after optimization)

\begin{tabular}{|c|c|c|c|c|c|c|c|}
\hline & $a_{1}(-)$ & $a_{2}(T)$ & $a_{3}\left(T^{2}\right)$ & $a_{5}(1 / T)$ & $a_{6}(\ln T)$ & $a_{7}(1 /(T-263))$ & $a_{8}(1 /(680-T))$ \\
\hline$\beta^{0}\left(\mathrm{Na}^{+} / \mathrm{SO}_{4}{ }^{2-}\right)$ & 107.35561 & 0.04794672 & -0.00002034 & -2736.492 & -19.41903 & -0.1243008 & 0 \\
\hline$\beta^{1}\left(\mathrm{Na}^{+} / \mathrm{SO}_{4}{ }^{2-}\right)$ & 1017.4354 & 0.45031511 & -0.00019494 & -26137.553 & -183.90464 & 0.00011838 & 851.963305 \\
\hline $\mathrm{C}^{\phi}\left(\mathrm{Na}^{+} / \mathrm{SO}_{4}{ }^{2-}\right)$ & -0.13574678 & 0.00013002 & 0 & 30.0944336 & 0 & 0.03864754 & 0 \\
\hline
\end{tabular}

10 
Table 5. Values of fitting constants for solubility products

\begin{tabular}{|c|c|c|c|c|c|}
\hline & $a_{1}(-)$ & $a_{2}(T)$ & $a_{3}(1 / T)$ & $a_{4}(\log T)$ & $a_{5}\left(1 / T^{2}\right)$ \\
\hline \multicolumn{6}{|l|}{$\mathrm{Na}_{2} \mathrm{SO}_{4} \cdot 10 \mathrm{H}_{2} \mathrm{O}$} \\
\hline (mirabilite) & $-4.86996660 E+03$ & $-1.50030705 \mathrm{E}+00$ & $1.19561391 E+05$ & $1.98633627 \mathrm{E}+03$ & 0 \\
\hline $\mathrm{Na}_{2} \mathrm{SO}_{4}$ (thenardite) & $-3.50862995 E+03$ & $-5.18430862 E-01$ & $1.99075358 \mathrm{E}+05$ & $1.26574808 \mathrm{E}+03$ & $-1.21641701 \mathrm{E}+07$ \\
\hline \multicolumn{6}{|l|}{$\mathrm{MgSO}_{4} \cdot 7 \mathrm{H}_{2} \mathrm{O}$} \\
\hline (epsomite) & $4.08480390 E+04$ & $7.49950739 \mathrm{E}+00$ & $-1.934676 E+06$ & $-1.521724 \mathrm{E}+04$ & $9.39747409 \mathrm{E}+07$ \\
\hline \multicolumn{6}{|l|}{$\mathrm{MgSO}_{4} \cdot 6 \mathrm{H}_{2} \mathrm{O}$} \\
\hline (hexahydrite) & $5.43604369 \mathrm{E}+03$ & 5.61493175E-01 & $-3.5461667 E+05$ & $-1.8930412 \mathrm{E}+03$ & $2.38767356 \mathrm{E}+07$ \\
\hline $\mathrm{MgSO}_{4} \cdot \mathrm{H}_{2} \mathrm{O}$ (kieserite) & $5.39329145 E+03$ & $5.18715131 \mathrm{E}-01$ & $-3.7474065 E+05$ & $-1.8602601 \mathrm{E}+03$ & $2.78132757 E+07$ \\
\hline \multicolumn{6}{|l|}{$\mathrm{Na}_{2} \mathrm{SO}_{4} \cdot \mathrm{MgSO}_{4} \cdot 4 \mathrm{H}_{2} \mathrm{O}$} \\
\hline (bloedite) & $3.56483519 \mathrm{E}+01$ & $-6.58258168 \mathrm{E}-02$ & $-5.4674363 E+03$ & 0 & 0 \\
\hline $3 \mathrm{Na}_{2} \mathrm{SO}_{4} \cdot \mathrm{MgSO}_{4}$ & $1.09286124 \mathrm{E}+01$ & $-4.26072730 \mathrm{E}-02$ & 0 & 0 & 0 \\
\hline $\mathrm{Na}_{2} \mathrm{SO}_{4} \cdot \mathrm{MgSO}_{4} \cdot 2.5 \mathrm{H}_{2} \mathrm{O}$ & $6.56596356 \mathrm{E}+00$ & $-2.73680649 \mathrm{E}-02$ & 0 & 0 & 0 \\
\hline
\end{tabular}




\begin{tabular}{|c|c|c|c|c|}
\hline Type of data & $\mathbf{T}\left({ }^{\circ} \mathrm{C}\right)$ & $\mathrm{m}\left(\mathrm{mol} . \mathrm{kg}^{-1}\right)$ & Experimental error & Ref. \\
\hline \multirow{5}{*}{ Osmotic coefficient } & 99.6 & $1.9-4.75$ & & Patterson et al., 1960 \\
\hline & 121.1 & $1.56-5.1$ & & Soldano and Patterson, 1962 \\
\hline & 25 & $0.925-3.61$ & & Rard and Miller, 1981 \\
\hline & $109.99,140.07$ & $1.38-5$ & & Holmes and Mesmer, 1983 \\
\hline & 25 & $0.5-1.3$ & & Archer and Rard, 1998 \\
\hline \multirow[t]{2}{*}{ Heat capacity } & $80-200$ & $0.18-0.92$ & $\pm 0.003 \mathrm{cal} \mathrm{g}^{-1} \cdot \mathrm{K}^{-1}$ & Likke and Bromley, 1973 \\
\hline & $0-90$ & $0.17-1.35$ & - & Zaytsev and Aseyev, 1992 \\
\hline
\end{tabular}




\begin{tabular}{|c|c|c|c|c|c|c|c|}
\hline & $a_{1}(-)$ & $a_{2}(T)$ & $a_{3}\left(T^{2}\right)$ & $a_{5}(1 / T)$ & $a_{6}(\ln T)$ & $a_{7}(1 /(T-263))$ & $a_{8}(1 /(680-T))$ \\
\hline$\beta^{2}\left(\mathrm{Mg}^{2+} / \mathrm{SO}_{4}{ }^{2-}\right)$ & $7.58048471 \mathrm{E}+04$ & $6.53134854 \mathrm{E}+01$ & $-4.388932 \mathrm{E}-02$ & $-1.05904 \mathrm{E}+06$ & $-1.544154 \mathrm{E}+04$ & $-1.36617 \mathrm{E}-01$ & $4.6838757 \mathrm{E}+04$ \\
\hline $\mathrm{C}^{\phi}\left(\mathrm{Mg}^{2+} / \mathrm{SO}_{4}{ }^{2-}\right)$ & $-9.8373402 E+01$ & $-7.007396 \mathrm{E}-02$ & $4.58738 \mathrm{E}-05$ & $1.7915821 \mathrm{E}+03$ & $1.93122662 \mathrm{E}+01$ & $9.40941 \mathrm{E}-06$ & $-3.159734 \mathrm{E}+02$ \\
\hline
\end{tabular}

